\title{
High Mn TWIP Steels for Automotive Applications
}

\author{
B. C. De Cooman ${ }^{1}$, Kwang-geun Chin ${ }^{2}$ and Jinkyung Kim ${ }^{1}$ \\ ${ }^{1}$ Graduate Institute of Ferrous Technology \\ Pohang University of Science and Technology, Pohang \\ 2POSCO Technical Research Laboratories, Gwangyang \\ South Korea
}

\section{Introduction}

Modern car design puts an increasing emphasis on the notion that a material used in building the body-in-white (BIW) should be selected on the basis of how well it helps achieving specific engineering targets such as low vehicle weight, high passive safety, stability, stiffness, comfort, acoustics, corrosion, and recycling. Steel is at present still the material of choice for car bodies, with $99 \%$ of the passenger cars having a steel body, and 60 $70 \%$ of the car weight consisting of steel or steel-based parts. The automotive industry is however continuously making excursions in the area of light materials applications. At present, most car makers are routinely testing multi-materials concepts, which are not limited to the obvious use of light materials for closures, e.g. the use of $\mathrm{Al}$ for the front lid or thermosetting resins for trunk lids. The steel industry has made a sustained effort to innovate and create advanced steels and original steel-based solutions and methods in close collaboration with the manufacturers by an early involvement in automotive projects, but also by involving automakers in their own developments. Carmakers have increasingly built passenger cars with body designs which emphasize passenger safety in the event of a collision, and most passenger cars currently achieve high ratings in standardized crash simulations such as the EURO NCAP or the North American NHST tests. The safety issue directly related to the BIW materials is passive safety. High impact energy absorption is required for frontal crash and rear collision, and anti-intrusion properties are required in situations when passenger injury must be avoided, i.e. during a side impact and in case of a roll over, with its associated roof crush. Increased consumer expectations have resulted in cars which have steadily gained in weight as illustrated in figure 1 . This weight spiral is a direct result of improvements in vehicle safety, increased space, performance, reliability, passenger comfort and overall vehicle quality. This trend has actually resulted in an increased use of steel in car body manufacturing in absolute terms, and this increase may in certain cases be as high as $25 \%$. The weight issue is therefore high on the agenda of BIW design, as it is directly related to environmental concerns, i.e. emissions of $\mathrm{CO}_{2}$, and the economics of the gas mileage. Reports on weight saving resulting from the use of Advanced High Strength Steels (AHSS) are difficult to evaluate as these tend to focus on the use of advanced steels and improved designs for a single part, rather than the entire car body. The use of Dual Phase (DP) and Transformation-Induced Plasticity (TRIP) steels has been 
reported to result in a weight saving in the range of $10-25 \%$. Similar weight reductions of about $25 \%$ are reported for the use of stainless steels. The potential for weight reductions become very important when very high strength steels are considered.

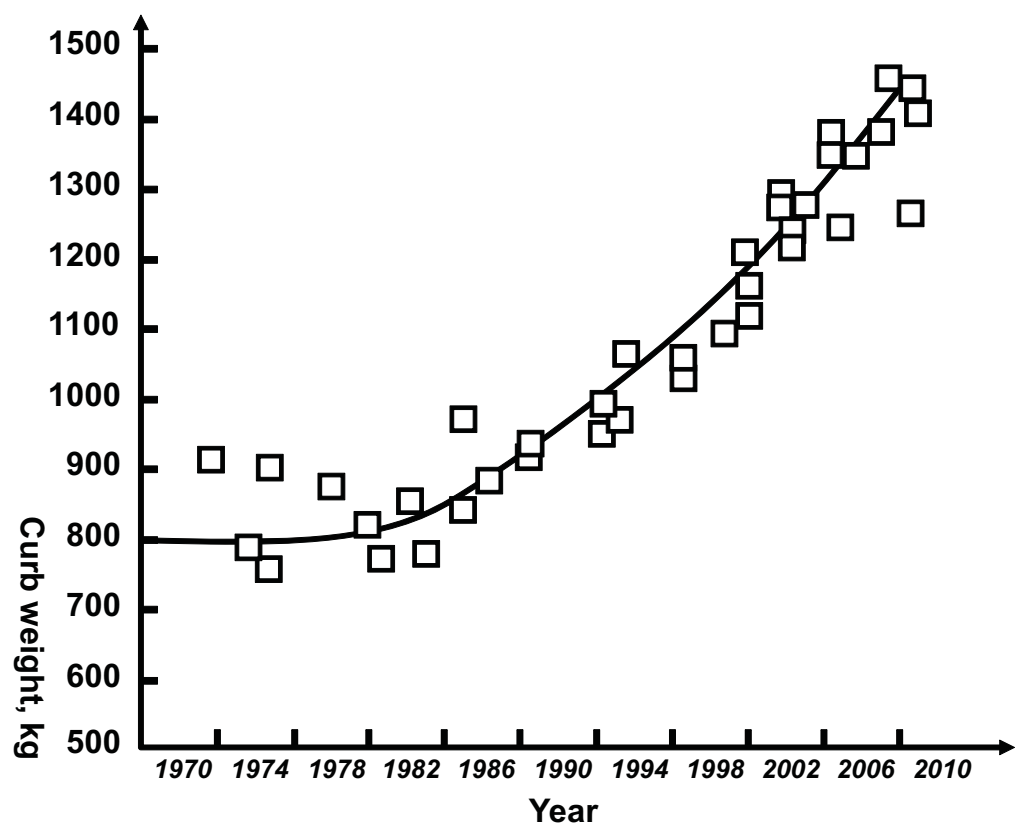

Fig. 1. Midsize passenger car weight increase in the EU. The weight increase is close to $90 \%$ for the period of 1970 to 2010.

Weight reductions of about $30-40 \%$ are typically reported for $1300-1500 \mathrm{MPa}$ steels. A $36 \%$ weight reduction can be expected when a body part used as anti-intrusion barrier is made of press hardening 22Mn5B steel. Most industry experts agree that, as illustrated in figure 2, steel based parts designs using advanced high strength steels offer both the potential for vehicle mass containment and lower production cost. Hence, when material-specific properties are considered, there is an increasingly important interest in very high strength materials. This has been the driving force behind most of the current automotive steel research efforts. This is obvious when one considers the need for the increased strength for parts related to passenger safety, such as the B-pillar, an essential element for passenger protection in side impact collisions.

DP and TRIP steels are now well established as AHSS, with major applications in BIW parts related to crash energy management. In addition to a high strength, a high stiffness and only very low levels of deformations, typically less than $5 \%$, may be allowed for these parts. Strength levels as high as $1800 \mathrm{MPa}$ have been mentioned as future requirements for antiintrusion parts. Whereas press-formable $\mathrm{CMnB}$ grades are receiving attention for the Bpillar and front-rear reinforcements, there is still considerable interest in TRIP and DP steels. In the case of DP grades the emphasis is on front end applications and exterior panels. Having said this, standard high strength micro-alloyed steels continue to be still being widely used. Two decades ago most BIW designs were based on steels with Ultimate Tensile 
Strength (UTS) values in the 200-300MPa range. Recent BIW designs tend to use much more high strength steels. Whereas less low strength steels ( $\mathrm{YS}<180 \mathrm{MPa})$ are being used, mainly for outer body parts, there is a pronounced increase in the use of High Strength Steels (HSS), with a yield strength (YS) $>300 \mathrm{MPa}$, Very High Strength Steels (VHSS) with a YS $>500 \mathrm{MPa}$, and Ultra High Strength Steels (UHSS) with UTS values up to $1500 \mathrm{MPa}$. This increased use of high strength steel grades has resulted in a moderate relative decrease of steel mass per car body.

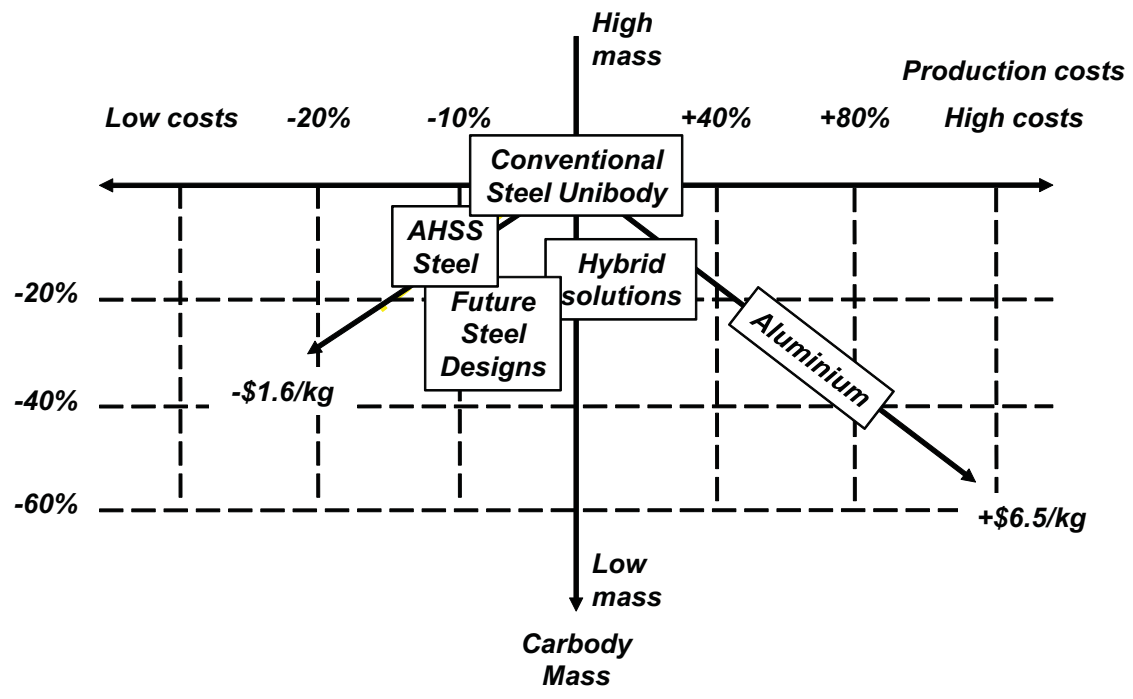

Fig. 2. Comparison of the production cost and vehicle mass containment for designs based on different material selections.

The present contribution reviews the important development of ultra-ductile TWIP steel for BIW applications. FeMn TWIP is a high-strength steel concept with superior formability, which may be close to being produced industrially. High manganese TWIP steels are highly ductile, high strength Mn austenitic steels characterized by a high rate of work hardening resulting from the generation of deformation-nucleated twins (Grassel et al., 1997; Grassel et al., 2000; Frommeyer, 2003; Prakash et al., 2008). Their Mn content is in the range of 15-30 mass \%. Alloying additions of $\mathrm{C}, \mathrm{Si}$ and/or $\mathrm{Al}$ are needed to obtain the high strength and the large uniform elongation associated with strain-induced twinning. Depending on the alloy system, the carbon content is either low, i.e. less than 0.05 mass- $\%$, or high, typically in the range of $0.5-1.0$ mass- $\%$. Si and $\mathrm{Al}$ may be added to achieve a stable fully austenitic microstructure with low stacking fault energy in the range of 15$30 \mathrm{~mJ} / \mathrm{m}^{2}$. High Mn alloys characterized by strength ductility products 40.000 $60.000 \mathrm{MPa} \%$ have reached the stage of large scale industrial testing and the industrial focus is mainly on TWIP steels with the following compositional ranges: $15-25$ mass- $\% \mathrm{Mn}$, with $0-3 \% \mathrm{Si}, 0-3 \% \mathrm{Al}$ and 200-6000ppm C. The dominant deformation mode in TWIP steel is dislocation glide, and the deformation-induced twins gradually reduce the effective glide distance of dislocations which results in the "Dynamical Hall-Petch effect" illustrated in the schematic of figure 3. 

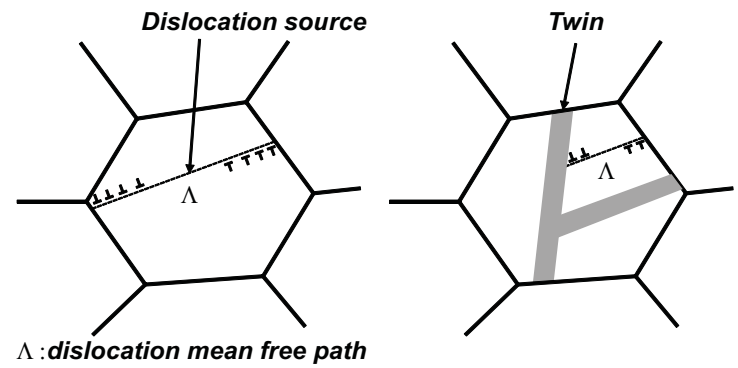

Fig. 3. Illustration of the dynamical Hall-Petch effect. Mechanical twins are formed due to the low stacking fault energy. They gradually reduce the effective glide distance of dislocations, resulting in the very high strain hardening observed in TWIP steel.

The mechanical properties of typical TWIP steels are reviewed in figure 4 . These steels have received attention only recently, and the early work on high Mn ferrous alloys by Schuman (Schuman, 1971) in Germany, Remy and Pineau (Remy \& Pineau, 1977) in France and Kim (Kim, 1993; Kim et al., 1993) in South Korea did not receive much attention originally. The work of Frommeyer (Grassel et al., 1997; Grassel et al., 2000; Frommeyer, 2003) at the Max Planck Institute in Dusseldorf, Germany, and the interest in advanced high strength steels from the automotive industry renewed the interest in the properties of high Mn TWIP steels and mainly three types of TWIP steel compositions have been extensively investigated: Fe$22 \% \mathrm{Mn}-0.6 \% \mathrm{C}$ (Allain, 2004), Fe-18\%Mn-0.6\% C, Fe-18\%Mn-0.6\%C-1.5\% Al (Kim et al., 2006) and the low carbon Fe-25\%-30\%Mn-3\%Si-\% Al (Grassel et al., 2000). The high rate of strain hardening associated with the deformation twinning phenomenon allows for the combination of higher strengths and higher uniform elongations, as illustrated in figure 5 which compares the properties of conventional multi-phase TRIP steel with those of TWIP steel.

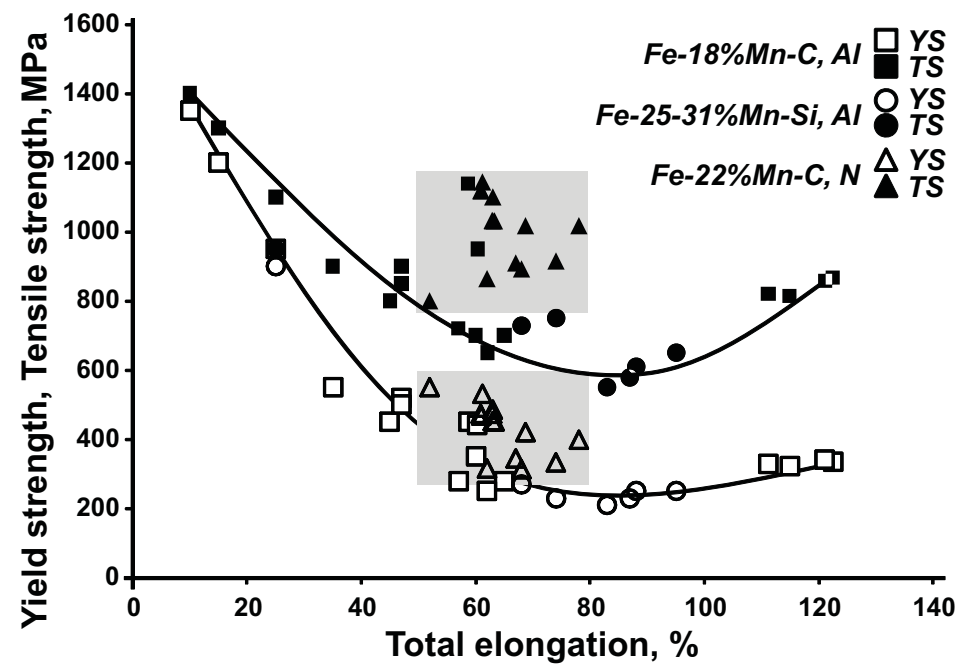

Fig. 4. Typical ranges for the mechanical properties of TWIP steel. 


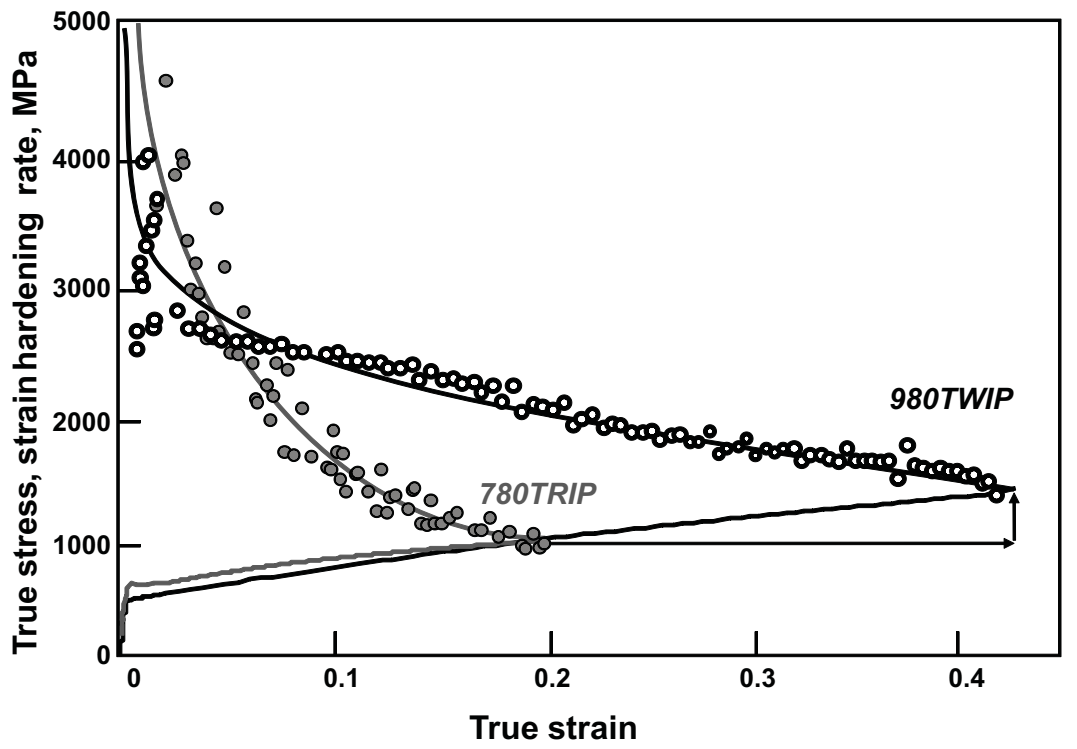

Fig. 5. Comparison of the stress-strain curves and the strain hardening rate for TRIP and TWIP steel. TWIP steel has a uniform elongation twice that of TRIP steel and a considerably higher ultimate strength.

\section{Thermodynamic properties of TWIP steel}

The Fe-Mn equilibrium phase diagram has recently been revised (Witusiewicz et al., 2004). On the Fe rich side of the diagram, the binary system would appear to be relatively simple with an open $\gamma$-loop. The meta-stable Fe-Mn diagram (figure 6) however reveals much more of the information which is required to understand the microstructures observed in practical non-equilibrium conditions. Between 5 mass- $\%$ and 25 mass- $\%$ of $\mathrm{Mn}$, the room temperature multi-phase microstructure of Fe-Mn alloys is dominated by the presence of $\alpha^{\prime}$ martensite, at low Mn contents, and $\varepsilon$-martensite, at higher Mn content.

Small Mn additions have a pronounced hardenability effect, resulting in the formation of cubic $\alpha^{\prime}$ martensite. At higher Mn contents h.c.p. $\varepsilon$-martensite is formed. Both types of martensite are also generated by stress and strain-induced transformations of the retained austenite phase. Stabilizing the austenite at room temperature requires $\mathrm{Mn}$ contents in excess of 27 mass- \% in the binary Fe-Mn alloy system. In order to obtain a stable room temperature austenite phase in alloys with less than 25 mass- $\%$ of $\mathrm{Mn}$, the formation of $\alpha^{\prime}$ and $\varepsilon$ martensite must be suppressed. This can be done by carbon additions. Carbon additions of approximately 0.6 mass- $\%$ make it possible to obtain uniform, carbide-free, austenitic microstructures and avoid the formation of $\varepsilon$-martensite (Schumann, 1971). Higher carbon additions result in $\mathrm{M}_{3} \mathrm{C}$ carbide formation.

Figure 7 illustrates the microstructure of a Fe- $18 \% \mathrm{Mn}-0.6 \% \mathrm{C}$ TWIP steel. The structure is single phase austenitic, with relatively coarse grains, which may contain wide recrystallization twins. The XRD results also illustrate the fact that this TWIP steel does not transform to martensite during straining. 

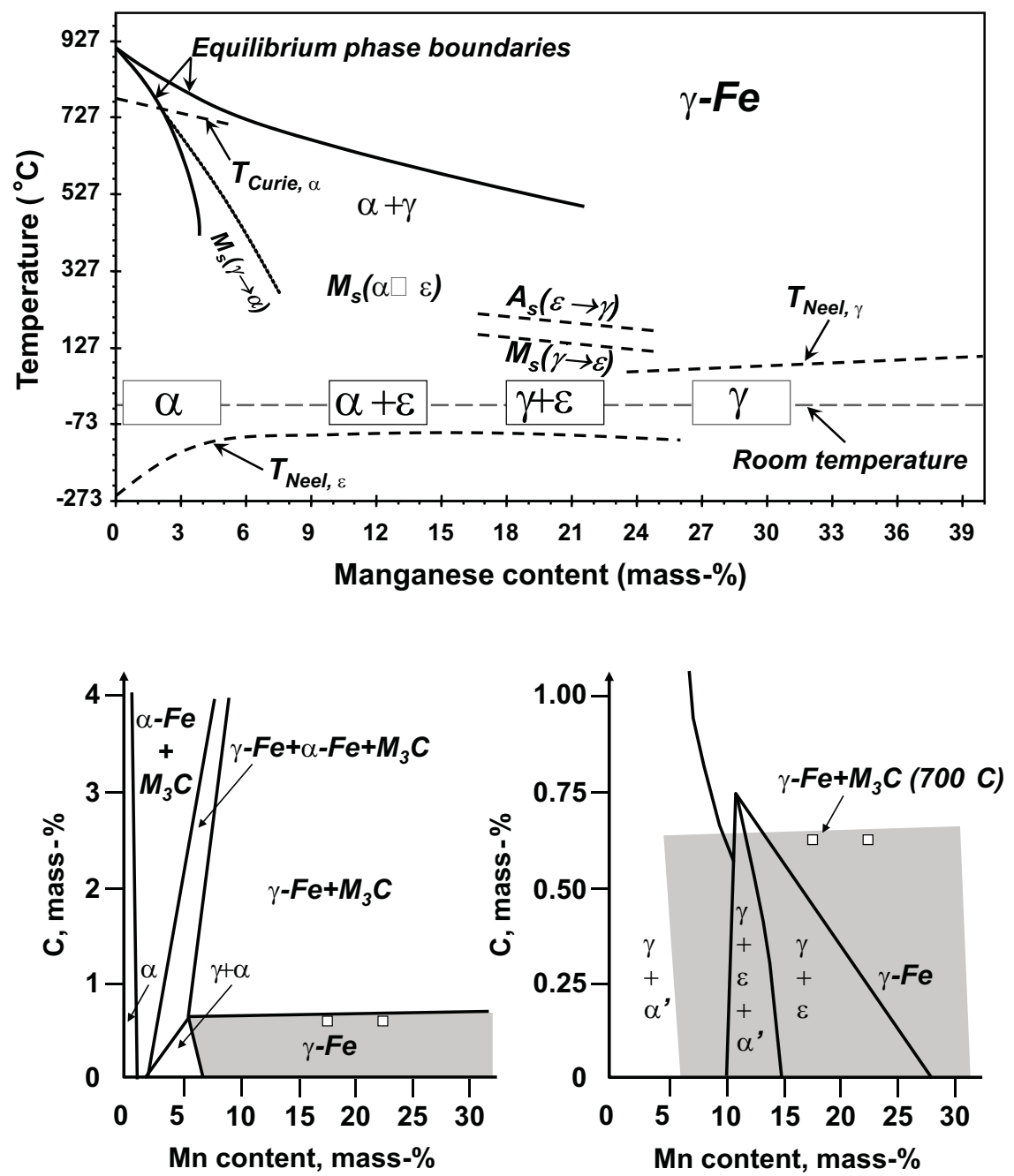

Fig. 6. (Top) Meta-stable Fe-Mn Phase diagram. (Below, left) Fe-rich corner of the Fe-Mn-C equilibrium phase diagram at $700^{\circ} \mathrm{C}$ showing the austenite stability range in grey. (Below, right) Superposition of the $700^{\circ} \mathrm{C}$ austenite stability range and the microstructure observed after quenching to room temperature from $950^{\circ} \mathrm{C}$.

An alternative approach to obtain TWIP steel with uniform, carbide-free, austenitic microstructures is to use a high Mn content and avoid carbon additions. This TWIP steel composition concept typically requires $\mathrm{Si}$ and $\mathrm{Al}$ additions to control the stacking fault energy. The importance of the $\mathrm{Al}$ additions cannot be underestimated and needs further attention as it results in much improved TWIP properties. It has been shown by Jung et al. (2008) that even small additions of Al facilitated the TWIP effect and they reported that the suppression of $\varepsilon$-martensite was achieved after addition of 1.5 mass- $\%$ Al to a Fe- $15 \% \mathrm{Mn}$ $0.6 \%$ C steel. 


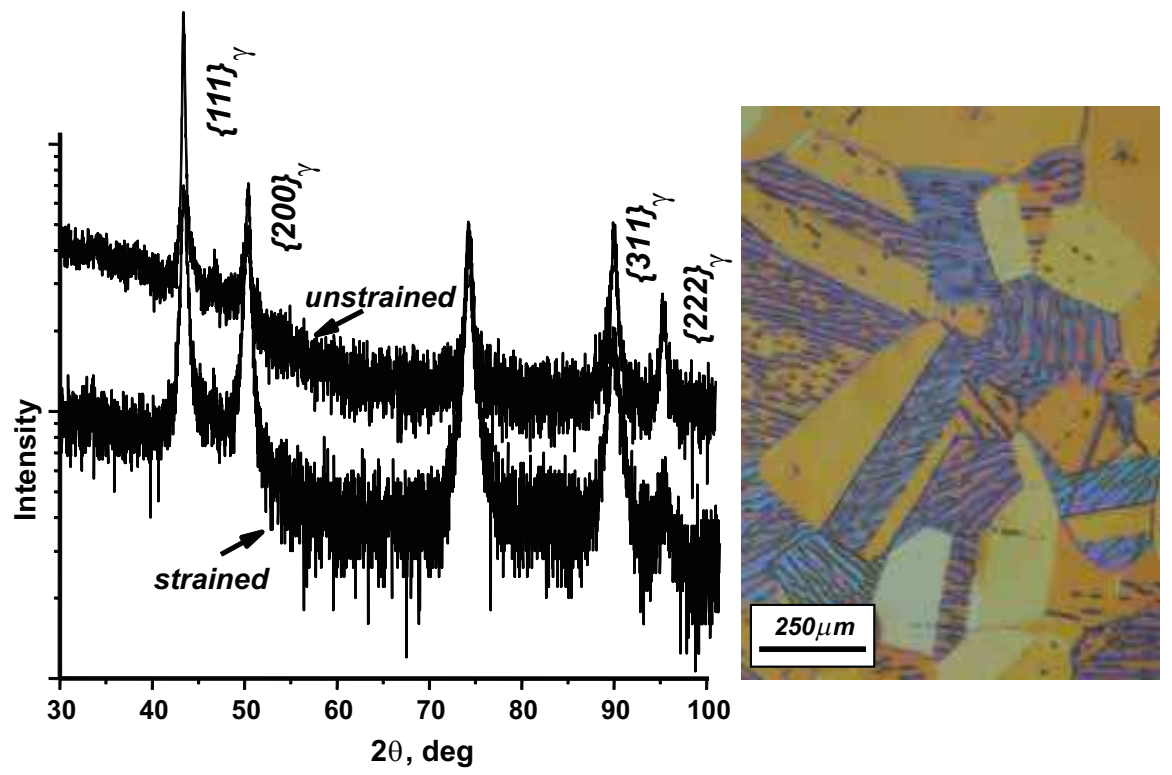

Fig. 7. XRD data for unstrained and strained Fe- $18 \%$ Mn-0.6\%C TWIP steel (left). The log scale was used for the intensity to emphasize the possible presence of small $\alpha^{\prime}$ and $\varepsilon$ diffraction peaks, which are clearly absent. Corresponding optical micrograph (right) obtained by color etching.

\section{Mechanical properties of TWIP steel}

TWIP steel research currently focuses on the influence of the alloy composition on the microstructure evolution during deformation and the resulting mechanical properties. In TWIP steel deformation is achieved by dislocation motion and twinning. The TWIP-effect is believed to be due mainly to a dynamic Hall-Petch effect. As the formation of mechanical twins involve the creation of new crystal orientations, the twins progressively reduce the effective mean free path of dislocations and increase the flow stress, resulting in a high strain hardening behavior. The best way to gain insight into the deformation behavior of TWIP steels is by TEM studies, as the twinning microstructure is very fine. Typical TEM observations are illustrated in figure 8 . The dislocations are clearly widely dissociated. In addition, wide stacking faults are often found to be emitted by grain boundaries. At low strains, the dislocation density increases and the grain boundaries seem to be particularly effective source of isolated stacking faults. Therefore, the deformation mechanism of TWIP steel at low strains is considered to be planar slip and the formation of wide stacking faults. The onset of twinning requires multiple slip within deformed grains. At $20 \%$ strain, the higher dislocation density between the deformation twins clearly shows that twin boundaries act as effective barriers for dislocation movement. Frequently one twinning system is activated, together with dislocation glide. These high aspect ratio twins cross the entire grain. In addition, the twins are internally faulted. High resolution TEM clearly reveals their very narrow width. The twins are very thin and there seems to be a continuous nucleation of new deformation twins of increasingly smaller size. Consequently, the twin 
volume fraction does not represent a large portion of the total volume. This observation seems to be in agreement with recent constitutive models of TWIP steels. The SFE plays an essential role in the occurrence of the TWIP effect. Although the role of deformationinduced twins will be mainly be discussed in the following paragraphs, it must not be forgotten that the rate of dislocation accumulation will automatically increase when an alloy has a low SFE, independently of twin formation, as the larger dissociation width will more effectively reduce the cross-slip and result in a higher rate of dislocation accumulation. As shown in figure 9, it is essential for the occurrence of the strain-induced twinning that the SFE be within a very specific range to observe mechanical twin formation. A very low SFE results in the strain-induced transformation to either $\alpha^{\prime}$ or $\varepsilon$ martensite. A low SFE, i.e. less that $<20 \mathrm{~mJ} / \mathrm{m}^{2}$, favors the $\gamma \rightarrow \varepsilon$ transformation. As the SFE is an essential parameter, there has been a considerable interest in determining its value for TWIP steels. There is still considerable uncertainty about the exact value of the SFE in Mn alloys, and whereas the theoretical evaluations agree on the range there is still considerable scatter in the reported SFE values. There are currently no experimental SFE available for most TWIP alloy systems, but a considerable number of theoretical calculations are available in the literature. From a theoretical point of view, the SFE is proportional to the f.c.c. and h.c.p. free energies difference, $\Delta G^{\gamma-\varepsilon}$. Interfacial energy, $\Delta G^{\gamma-\varepsilon}$ surface, and magnetic energy contribution, $\Delta \mathrm{G}^{\gamma-\varepsilon}$ magnetic, to the stacking fault energy need to be taken into account as they may have a significant influence:

$$
\gamma=\frac{1}{8 \cdot V^{2 / 3}} \cdot\left(\Delta G_{b u l k}^{\gamma \rightarrow \varepsilon}+\Delta G_{\text {surface }}^{\gamma \rightarrow \varepsilon}+\Delta G_{\text {magnetic }}^{\gamma \rightarrow \varepsilon}\right)
$$

The interfacial energy can be taken as the coherent twin boundary energy and the energy of the twinning dislocations. The high value of the stacking fault energy at the f.c.c./h.c.p. transition temperature in austenitic stainless steels has been explained by consideration of magnetic effects.

Most authors report that stable, fully austenitic microstructures with TWIP properties have a SFE in the range of $20 \mathrm{~mJ} / \mathrm{m}^{2}$ to $30 \mathrm{~mJ} / \mathrm{m}^{2}$ (Schuman, 1971; Adler et al., 1986; Miodownik, 1998; Yakubtsov et al., 1999; Allain et al., 2004). Carbon additions are required to obtain a low SFE, but the addition of carbon is limited by the formation of $\mathrm{M}_{3} \mathrm{C}$ carbide.

Some data on the effect of the carbon content in Fe-22\%Mn-C alloys has been reported by Yakubtsov et al. (1999). They report that the SFE of a Fe-22\%Mn alloy is approximately $30 \mathrm{~mJ} / \mathrm{m}^{2}$. Carbon additions less than 1 mass-\% reduce the SFE to approximately $22 \mathrm{~mJ} / \mathrm{m}^{2}$. At higher carbon contents the SFE is reported to increase.

The critical stacking fault region to achieve twinning-induced plasticity is still unclear. Frommeyer et al. [3] indicate that whereas a SFE larger than about $25 \mathrm{~mJ} / \mathrm{m}^{2}$ will results in the twinning effect in a stable $\gamma$ phase, a SFE smaller than about $16 \mathrm{~mJ} / \mathrm{m}^{2}$, results in $\varepsilon$ phase formation. Allain et al. (2004) give a much narrower range. According to them the SFE should be at least $19 \mathrm{~mJ} / \mathrm{m}^{2}$ to obtain mechanical twinning. They mention that a SFE less than $10 \mathrm{~mJ} / \mathrm{m}^{2}$ results in $\varepsilon$ phase formation. Dumay et al. (2008) mention that below a SFE of $18 \mathrm{~mJ} / \mathrm{m}^{2}$ twinning tends to disappear and is replaced by $\varepsilon$-platelets. They mention that a $\mathrm{SFE}$ of about $20 \mathrm{~mJ} / \mathrm{m}^{2}$ is needed for the best hardening rate. Jin et al. (2009) mention that a $\mathrm{SFE}$ value of $33 \mathrm{~mJ} / \mathrm{m}^{2}$ is required to obtain twinning in Fe- $18 \% \mathrm{Mn}-0.6 \% \mathrm{C}-1.5 \% \mathrm{Al}$. Recently, Kim et al. (2010) measured that the SFE of Fe-18\%Mn- $0.6 \% \mathrm{C}-1.5 \% \mathrm{Al}$ TWIP steel was $30 \pm 10 \mathrm{~mJ} / \mathrm{m}^{2}$ (figure 10). 

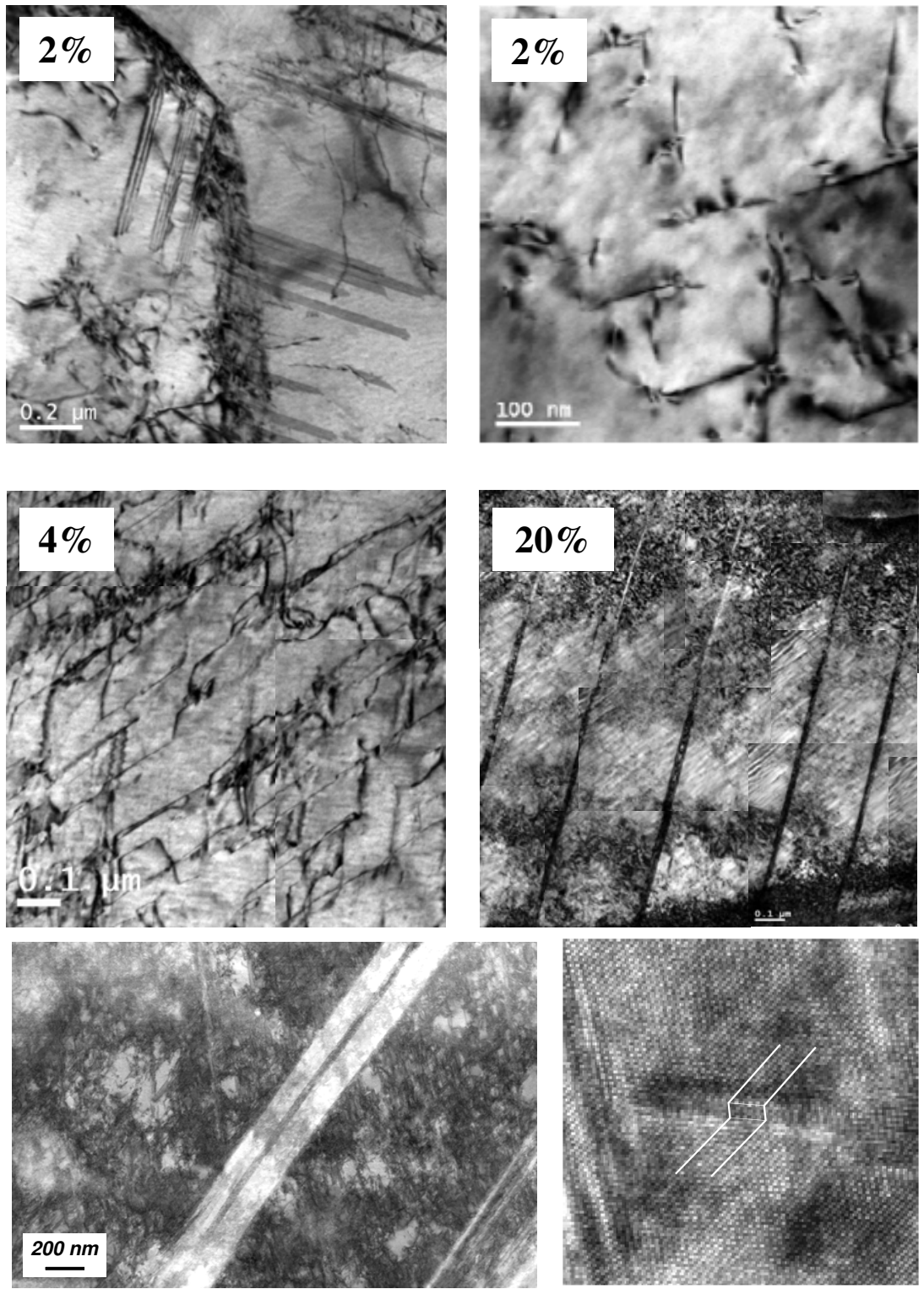

Fig. 8. (Top) TEM micrographs of TWIP steel after $2 \%, 4 \%$ and $20 \%$ of pre-straining showing that in the initial stages of deformation, the dislocation density increases and there is no formation of twins. In addition, some grain boundaries emit bundles of stacking faults. At higher strains, the early twins cross the entire grain. The twins often have an internal dislocation sub-structure. (Below, left) TEM micrograph of a TWIP steel deformed at high strains close to fracture. (Below, right) High resolution lattice image of a short secondary twin impinging on a larger primary twin located on the left hand side of the micrograph. 


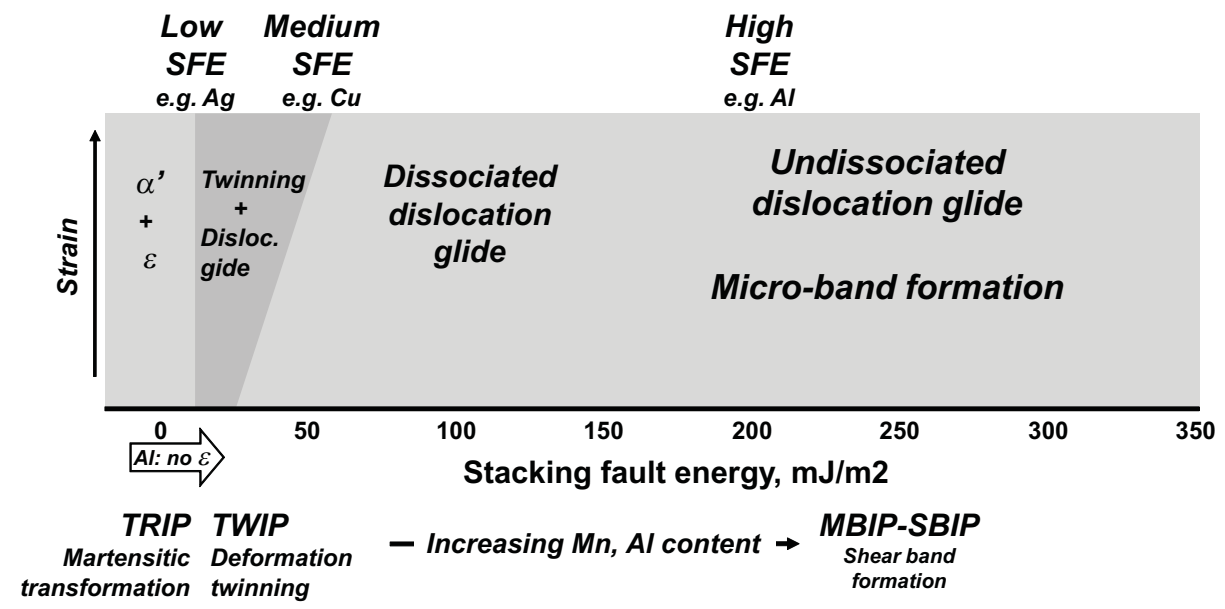

Fig. 9. Schematic showing the relation between SFE and the operating deformation mechanism in f.c.c. metals and alloys.
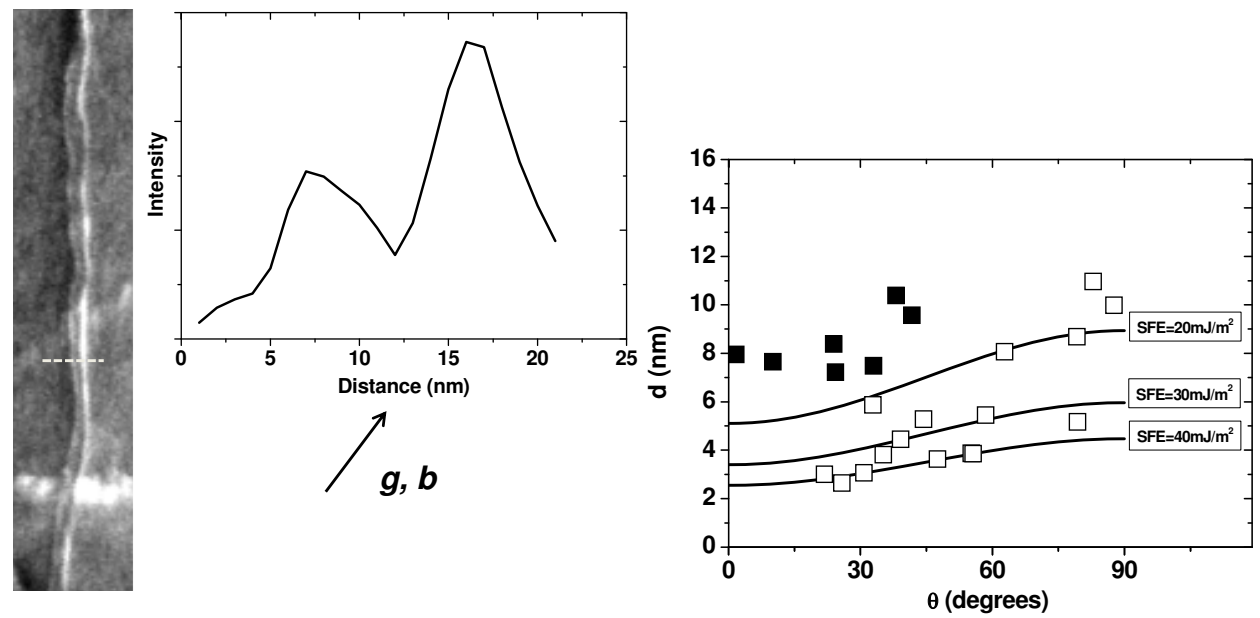

Fig. 10. (Left) Weak-beam dark field image of a dissociated dislocation on its glide plane. The SFE of this dislocation was $23.5 \mathrm{~mJ} / \mathrm{m}^{2}$ based on four measurements of the partial dislocation separation on this micrograph. (Right) Partial dislocation separation is a function of the angle between the Burgers vector of the perfect dislocation and the dislocation line. The experimental points are consistent with a SFE of $30 \pm 10 \mathrm{~mJ} / \mathrm{m}^{2}$.

The effect of $\mathrm{Al}$ addition to TWIP steel has received much attention as it has resulted in TWIP steels with improved properties and a lower sensitivity to delayed fracture. Al increases the SFE, it also lowers the strain hardening resulting in TWIP steels with slightly lower tensile strengths. Al also very effectively suppresses the $\gamma \rightarrow \varepsilon$ transformation. Instead, similar observations have been made for $\mathrm{N}$. Both $\mathrm{Al}$ and $\mathrm{N}$ reduced the stacking fault formation probability. The SFE for Fe-Mn-Si-Al TWIP steel has been studied by Huang et al. 
(2008). They have also studied the effect of $0.011-0.052 \%$ nitrogen on the SFE of Fe-20.24$22.57 \% \mathrm{Mn}-2-3 \% \mathrm{Si}-0.69-2.46 \% \mathrm{Al}$ containing $100 \mathrm{ppm}$ carbon, by means of $\mathrm{X}$ ray diffraction. Although they do not report actual SFE values, their results indicate that both $\mathrm{Al}$ and $\mathrm{N}$ are favorable for the formation of twins as they increase the SFE and decrease the stacking fault formation probability. Similarly Dumay et al. (2008) calculate that Al increases the SFE by about $+5 \mathrm{~mJ} / \mathrm{m}^{2}$ per added mass- $\%$ of $\mathrm{Al}$, whereas $\mathrm{Si}$ is also found to increase the SFE by about $+1 \mathrm{~mJ} / \mathrm{m}^{2}$ per mass-\% of Si. Their results are not confirmed by the experimental measurements of Tian et al. (2008) who measured the SFE measured for Fe-25\% Mn- $0.7 \% \mathrm{C}$ $\mathrm{Al}$ steel with $1.16 \%$ to $9.77 \%$ of $\mathrm{Al}$. They report a much smaller effect of $\mathrm{Al}$ on the increase of the SFE, about $+1.4 \mathrm{~mJ} / \mathrm{m}^{2}$ per added mass- $\%$ of $\mathrm{Al}$.

Although there is a general consensus that the stacking fault energy is an essential parameter, it is by no means proven that it is the single most important parameter controlling the TWIP mechanism. In fact, Wang et al. (2008) have remarked that it is rather surprising that only a very small difference in SFE of the order of $5-10 \mathrm{~mJ} / \mathrm{m}^{2}$ seemed to cause an apparently very sharp transition from strain-induced $\varepsilon$-martensite formation to strain-induced twinning. Recent experimental measurements on the nature of the stacking faults have resulted in the suggestions that $\varepsilon$-martensite formation and mechanical twinning is mediated by ESF and ISF respectively. Idrissi et al. (2009) studied the deformation mechanism of a two phase $\alpha+\gamma$ Fe-19.7\% Mn-3.1\% Al-2.9\%Si steel. Deformation at $86^{\circ} \mathrm{C}$ and $160^{\circ} \mathrm{C}$ resulted in $\varepsilon$-martensite and twinning at low temperature, and exclusively mechanical twinning at the high temperature. At room temperature only $\varepsilon$-martensite was observed. They argue that this was due to the presence of extrinsic SFs at lower temperatures acting as precursors to $\varepsilon$-martensite formation and ISF at higher temperatures acting as twin precursors.

\section{Strain-induced twinning}

Figure 11 compares the structure and the energy of the various planar faults which can occur in f.c.c. metals and alloys. It illustrates the relation between the h.c.p. structure and the extrinsic stacking faults and the relation between the coherent twin and the intrinsic stacking fault.

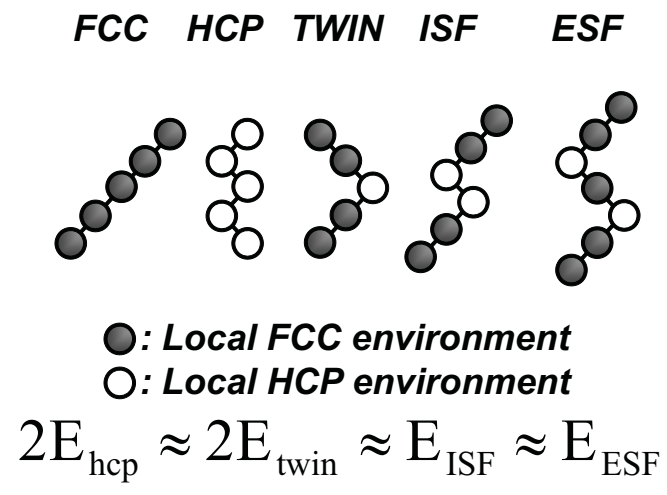

Fig. 11. Comparison of the structure and energy of the planar faults in f.c.c. metals and alloys. 
The nucleation of twins in TWIP steel does not seem to be a homogeneous process. Instead, the nucleation stage in deformation twinning is closely related to prior dislocation activity, as the process always occurs after some amount of prior dislocation generation and dislocation-dislocation interactions on different slip systems. Twins are initiated in special dislocation configurations created by these interactions generally resulting in multi-layer stacking faults which can act as twin nuclei.

The effect of the deformation twinning process is twofold: the twinning shear makes a relatively small contribution to the deformation and the twin boundaries, which act as barriers to dislocation motion, reduce the dislocation mean free path (Meyers et al., 2001).

The most likely mechanism for strain-induced twinning (figure 12) has been proposed by Venables (Venables, 1961; Venables, 1964; Venables, 1974). In a first stage a jog is created on a dislocation by dislocation intersection. This jog dissociates in a sessile Frank partial dislocation and a Shockley partial dislocation. When the partial dislocation moves under the influence of an externally applied force, it trails an intrinsic stacking fault and it rotates repeatedly around the pole dislocations, generating a twin in the process.
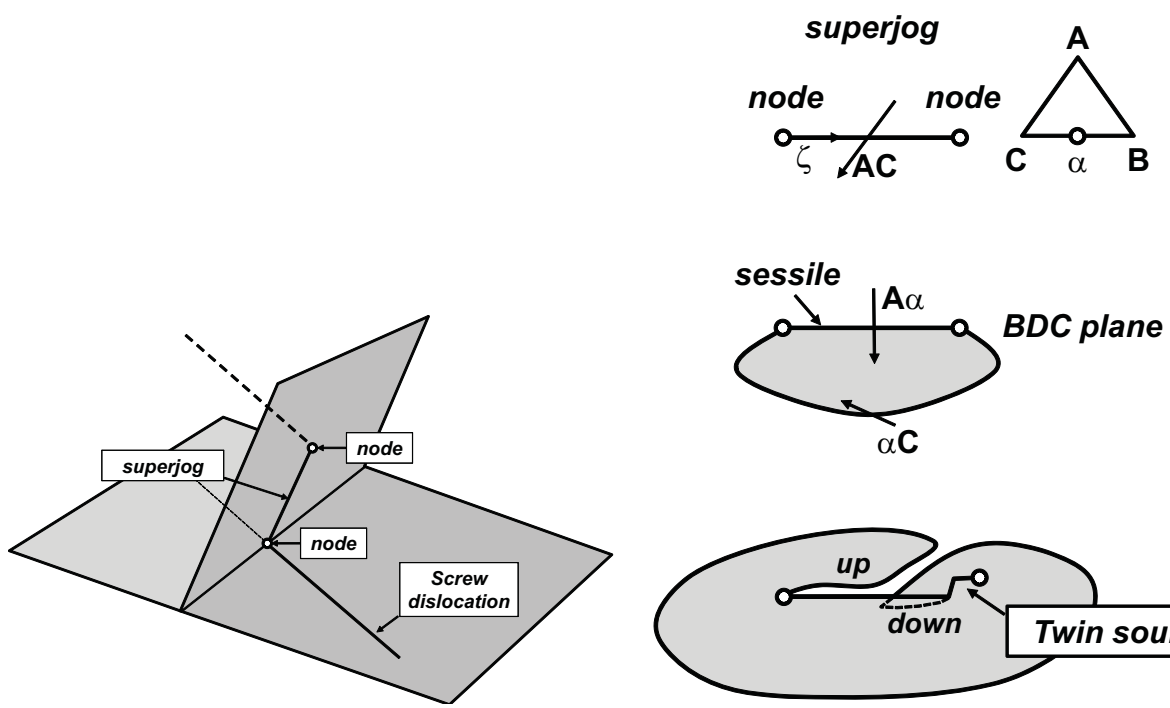

Fig. 12. Schematic showing the different stages in the Venables pole mechanism for straininduced twinning.

As the stress increases, the volume fraction of twins increase steadily, continuously dividing grains into smaller units. It can be considered a dynamic Hall-Petch effect as the effective grain size is continuously being decreased.

Glide type deformation-induced twinning mechanisms have also been proposed. In glide mechanisms it is assumed that the passage of identical a/ $6<112>$ type partials on successive $\{111\}$ planes. This process requires very high stresses with specific orientations. Glide sources are therefore less probable source of twins, but Bracke et al. (2009), who studied twinning in Fe-22\%Mn-0.5\%C TWIP steel by means of TEM, support a model for the creation of a three layer stacking fault acting as a twin nucleus. They report a critical shear stress for twinning to be $89 \mathrm{MPa}$. 
In the absence of preferred crystallographic orientations and assuming the orientation factors for twinning and slip are equal, the transition from slip only deformation to slip and twinning deformation occurs when the slip stress reaches the twinning stress. As there is no agreed model for twin formation, the stress required to nucleate a twin is difficult to compute without making some essential simplifications. In practice, the growth of a twin requires a much lower stresses than what is usually computed by models. Hence nucleating stresses must be due to local stress concentration, as externally applied tensile stresses result in homogeneous stresses too low to nucleate twins. The twinning stress increases with increasing SFE, and the stress required to nucleate a twin is related to the intrinsic stacking fault energy in a quadratic or linear manner (Muira et al., 1968). Byun (2003) derived the following equation for the twinning stress, assuming that partial dislocation breakaway was the mechanism for the initiation of deformation twinning:

$$
\tau_{T}=6.14 \cdot \frac{\gamma_{I S F}}{\left|\vec{b}_{p}\right|}
$$

The equation is illustrated in figure 13 for $\mathrm{SFE}=20 \mathrm{~mJ} / \mathrm{m}^{2}$.
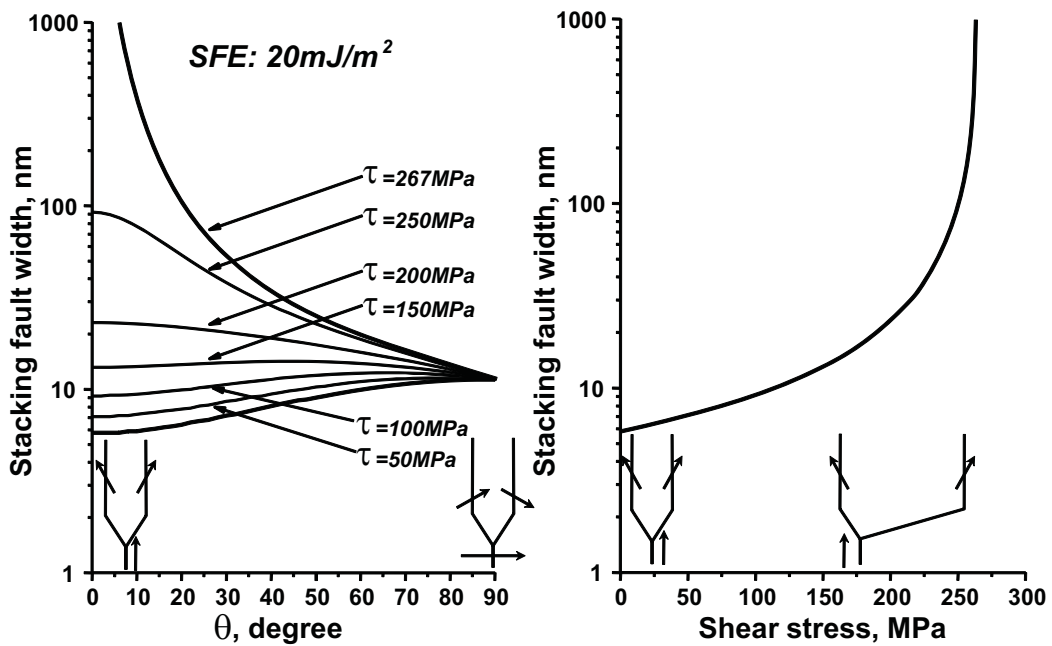

Fig. 13. Illustration of the Byun "infinite separation" approach for the determination of the twinning stress. This approach assumes that for dislocations close to the screw orientation, partial dislocation break-away is possible and that this process initiates deformationinduced twinning. For a SFE of $20 \mathrm{~mJ} / \mathrm{m}^{2}$ a tensile stress of approximately $820 \mathrm{MPa}$ is required. This is achieved at $20-25 \%$ of strain, i.e. a much higher stress than is needed to experimentally observe twinning.

Meyers et al., (2001) proposed a model where twins are formed at grain boundaries and he reports the following equation for the twinning stress:

$$
\sigma_{T}=M \cdot\left(\frac{n \cdot l \cdot E}{M \cdot A_{0}}\right)^{\frac{1}{1+m}} \cdot \dot{\varepsilon}^{\frac{1}{1+m}} \cdot e^{\frac{Q}{(m+1) \cdot R \cdot T}}
$$


The parameter $m$ relates the dislocation velocity to the applied shear stress. $n$ is the number of dislocations in the grain boundary pile up causing a local stress increase. The parameter 1 is the distance between the dislocation source and the grain boundary. E is Young's modulus. $\mathrm{Q}$ is the activation energy for dislocation motion. $\mathrm{M}$ is an orientation factor.

The grain size D may play a role in the value of the twinning stress and larger grains tend to expand the twinning domain:

$$
\sigma_{T}=\sigma_{T 0}+\frac{k_{T}}{\sqrt{D}}
$$

The $\mathrm{k}_{\mathrm{T}}$ value is usually much larger than the $\mathrm{k}_{\mathrm{y}}$ value for dislocation slip in the standard Hall-Petch relation.

Sevillano (2009) has recently proposed a strain-hardening model for TWIP steels by considering that its behavior is similar to that of a plastically heterogeneous composite. He argues that the observation of an important Bauschinger effect, the back stress contributing as much as half of the total stress, by Bouaziz et al. (2008) is due to the fact that the simultaneous deformation of the grains and their twinned parts requires the presence of a forward internal stress operating on the twin and a backward internal stress operating on the untwinned matrix. This is due to the fact that the twins must share similar strain components with their matrix. The twins must however have an important contribution to the strength, which can only be based on their small nanometer thickness. Bouaziz et al. (2008) however link the backstress to dislocations of a given slip system being stopped at grain and twin boundaries and developing a stress which prevents similar dislocations from moving ahead.

Jin et al. (2009) have studied the strain hardening of Fe-18\%Mn- $0.6 \% \mathrm{C}-1.5 \% \mathrm{Al}$ in detail and report that at large strains the deformation twinning rate greatly decreases deformation twins with different growth directions and that the amount of twinned volume is controlled not by the lateral growth of the deformation twins, but by the increase in the number of new deformation twins.

Various models have been proposed to model the TWIP-effect in high Mn steel in order to understand the parameters controlling their pronounced work-hardening. Bouaziz et al. (2001) and Allain et al. (2004) were probably the first to attempt to model the effect of the strain-induced twinning on the work-hardening of TWIP steel on a physical basis using the Kocks-Mecking (Kocks \& Meckings, 1981) approach. In their description the twins act as impenetrable obstacles. The model computes uniaxial tensile stress-strain curves on the basis of the evolution of the dislocation density and the twin volume fraction. Their description of the evolution of the dislocation density is given by:

$$
\begin{gathered}
\frac{d \rho}{d \gamma}=\frac{1}{b} \cdot\left(\frac{1}{d}+\frac{1}{t}+k \cdot \sqrt{\rho}\right)-f \cdot \rho \\
t=2 \cdot e \cdot \frac{1-F}{F}
\end{gathered}
$$

The twin volume fraction is given by:

$$
F=1-e^{-m \cdot \varepsilon}
$$

The SFE enters indirectly in the Bouaziz-Allain model through the value of the mparameter. Applying their model to Fe-22\%Mn-0.6\%C TWIP steel, they found the flowing 
values for the main parameters: $\mathrm{k}=0.011, \mathrm{f}=3$ and $\mathrm{m}=1$.95. Interestingly, $\mathrm{k}$ and $\mathrm{f}$ are exactly the same as for AISI 409 and 304L grades. The same authors described an extension to their original model using a visco-plastic description and a homogenization law to deal with a randomly oriented polycrystal. These results support the fact that the total volume fraction of the twins is very low and that plastic deformation is mainly achieved by dislocation glide. In contrast to recrystallization twins, deformation twins tend to be very thin. The twins are estimated to be $15 \mathrm{~nm}$ thick. Allain et al. (2004) also proposed a mechanism for the twinning behavior of the deformation-induced twins whereby in a first stage a few tens of nanometer thick twin will move until it reaches a strong boundary, a grain boundary or a twin boundary. In the second stage the twins thicken. They also notice that two twinning systems are sequentially activated in most grains. The first twins develop across the entire grain. The twins of second system develop between the primary twins and are much shorter and thinner.

Shiekhelsouk et al. (2009) developed a very detailed physically-based, micro-mechanical model incorporating elasto-visco-plasticity, to obtain a constitutive model for Fe- $22 \% \mathrm{Mn}$ $0.6 \%$ C TWIP steel using a randomly oriented representative volume element of 800 grains. They report that the twinned volume fraction is dependent on the grain orientation, and is less than 0.08 for a macroscopic strain of 0.4 .

Kim et al. (2010) used the Kubin-Estrin model (1986) to compute the strain hardening from the evolution of the coupled densities of the mobile dislocations, $\rho_{\mathrm{m}}$, and immobile forest dislocations, $\rho_{\mathrm{f}}$. In this model the two dislocation densities saturate at large strains and two dislocation densities are coupled via terms which simultaneously appear as annihilation terms in the evolution equation for $\rho_{\mathrm{m}}$ and as production terms in the evolution equation for $\rho_{\mathrm{f}}$. The following set of differential equations was used:

$$
\begin{aligned}
& \frac{d \rho_{m}}{d \varepsilon_{g}}=M\left[\frac{C_{1}}{b^{2}}\left(\frac{\rho_{f}}{\rho_{m}}\right)-C_{2} \rho_{m}-\frac{C_{3}}{b} \rho_{f}^{1 / 2}\right] \\
& \frac{d \rho_{f}}{d \varepsilon_{g}}=M\left[C_{2} \rho_{m}+\frac{C_{3}}{b} \rho_{f}^{1 / 2}-C_{4} \rho_{f}\right]
\end{aligned}
$$

In these equations $C_{1}$ is a production term, with forest obstacles acting as pinning points for fixed dislocation sources. $\mathrm{C}_{2}$ takes into account the mobile density decrease by interactions between mobile dislocations. $C_{3}$ describes the immobilization of mobile dislocations with a mean free path proportional to $\rho_{\mathrm{f}}^{1 / 2}$, assuming a spatially organized forest structure. $C_{4}$ is associated with the rearrangement and annihilation of forest dislocations by climb or crossslip.

The Bouaziz et al. (2001) expression for the twin spacing was modified to take into account the fact that as a set of parallel planar twins of identical thickness cross a grain, the areal fraction and the volume fraction of twins are the same means and the factor of 2 should not be considered, hence:

$$
t=e \frac{1-F}{F}
$$

where $t$ is the average twin spacing, e is the average twin thickness which is independent of strain, and $\mathrm{F}$ is the twin volume fraction.

Combining the three previous equations, the dislocation density evolution was expressed as follows: 


$$
\frac{d \rho}{d \varepsilon_{g}}=M\left[\frac{1}{b}\left(\frac{1}{d}+\frac{1}{t}+k \sqrt{\rho}\right)-k_{2} \rho\right]=M\left[\frac{1}{b}\left(\frac{1}{d}+\frac{1}{e} \cdot \frac{F}{1-F}+k \sqrt{\rho}\right)-k_{2} \rho\right]
$$

The twinning-related term is expected to result in a remarkable increase of the strain hardening behavior compared to the classical strain hardening behavior. A modification to these equations taking into account dynamic strain aging (DSA) was also included. The result for a $\mathrm{Fe}-18 \% \mathrm{Mn}-0.6 \% \mathrm{C}-1.5 \% \mathrm{Al}$ TWIP steel is shown in figure 14 . The model correctly predicts that the strain hardening $\mathrm{d} \sigma / \mathrm{d} \varepsilon$ has a more or less flat behavior in the intermediate strain levels, rather than continuously decreasing as it occurs in the case of high SFE metals. This sustained strain hardening level is due to the gradual decrease in the dislocation mean free path.

Dini et al. (2010) analyzed the dislocation density evolution in Fe-31\%Mn-3\%Al-3\%Si TWIP steel during straining by means of XRD. They calculate a large twin volume fraction of 0.56 at a strain of 0.4 . They report a value of $18 \mathrm{~nm}$ for the twin lamella thickness.

(a)
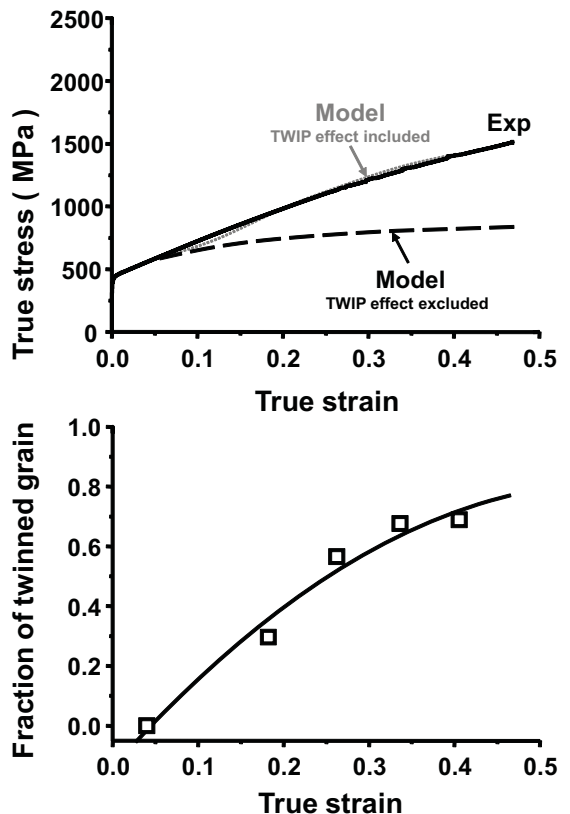

(b)

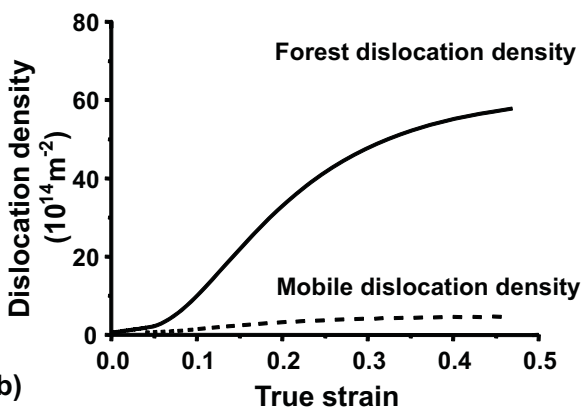

(d)

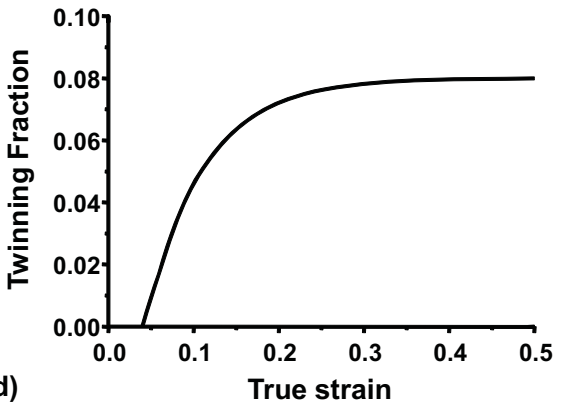

Fig. 14. (a) Comparison of the experimental true stress-true strain curves and the model calculation. (b) Mobile and forest dislocation density for twinned grains as a function of true strain. (c) The average volume fraction of twins inside a twinned grain as a function of true strain. (d) Fraction of twinned grain as a function of true strain.

\section{Forming properties}

The normal anisotropy and the strain hardening are usually considered the most important sheet forming properties. The normal anisotropy of Fe- $18 \% \mathrm{Mn}-0.6 \% \mathrm{C}-1.5 \% \mathrm{Al}$ TWIP steel, as measured in the RD, TD and at $45^{\circ}$ to $\mathrm{RD}$ is illustrated in figure 15 . The normal anisotropy 
value is relatively low, but this is expected to have a relatively low impact on the forming performance because of the high strain hardening coefficient, as illustrated in figure 16.

The strain hardening can be seen to increase steadily up to a strain of approximately 0.25 . At that stage the strain hardening assumes a constant value of about 0.5. Comparison of the data in figure 16 and the results of the model calculations shown figure 14(d) reveal that the strain hardening is closely related to the formation of strain-induced twins. It can also be seen that the strain hardening reaches a constant value at a strain of approximately 0.25 , which coincide with the saturation of the twin volume fraction.
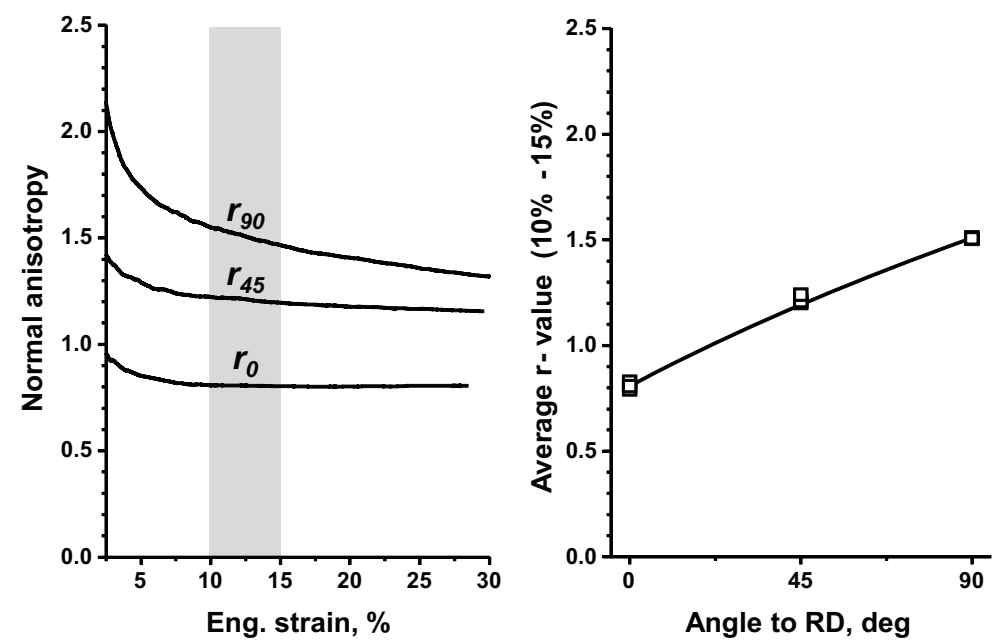

Fig. 15. Strain dependence of the normal anisotropy for tensile samples taken at $0^{\circ}, 45^{\circ}$ and $90^{\circ}$ to the rolling direction (left). Planar anisotropy in the $10 \%-15 \%$ strain range (right).

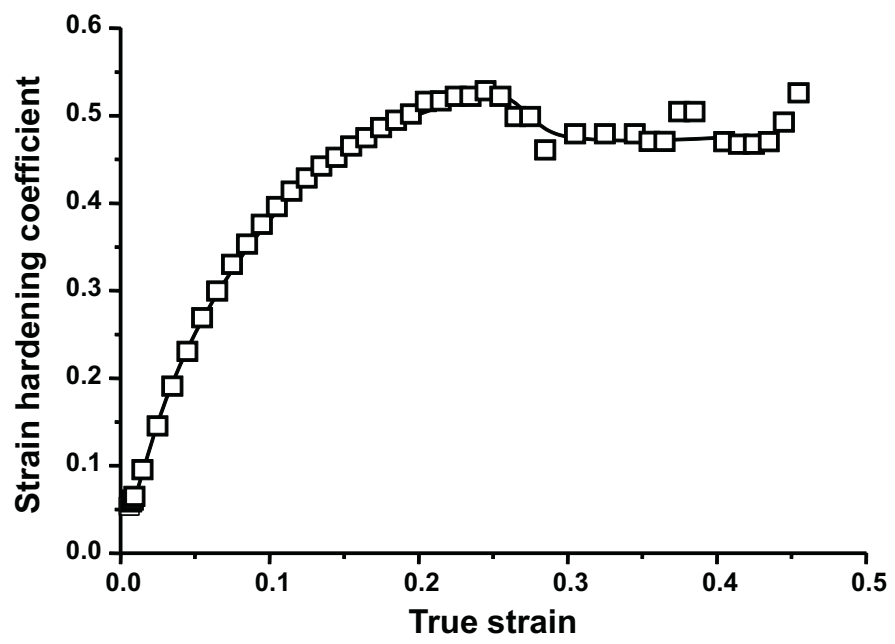

Fig. 16. Strain hardening of Fe- $18 \% \mathrm{Mn}-0.6 \% \mathrm{C}-1.5 \% \mathrm{Al}$ TWIP steel. 
The stretch forming properties of TWIP steel are considerably better than those of the other AHSS of similar strength level. The low r-value and the negative strain rate sensitivity results in low values when the starting hole is made using a method that leads to considerable deformation of the hole edge, such as hole punching. This is illustrated in figure 17.

Having said this, the actual forming performance of TWIP steel has proven to be excellent in practice. This is illustrated by the example of the shock absorber housing in figure 18.
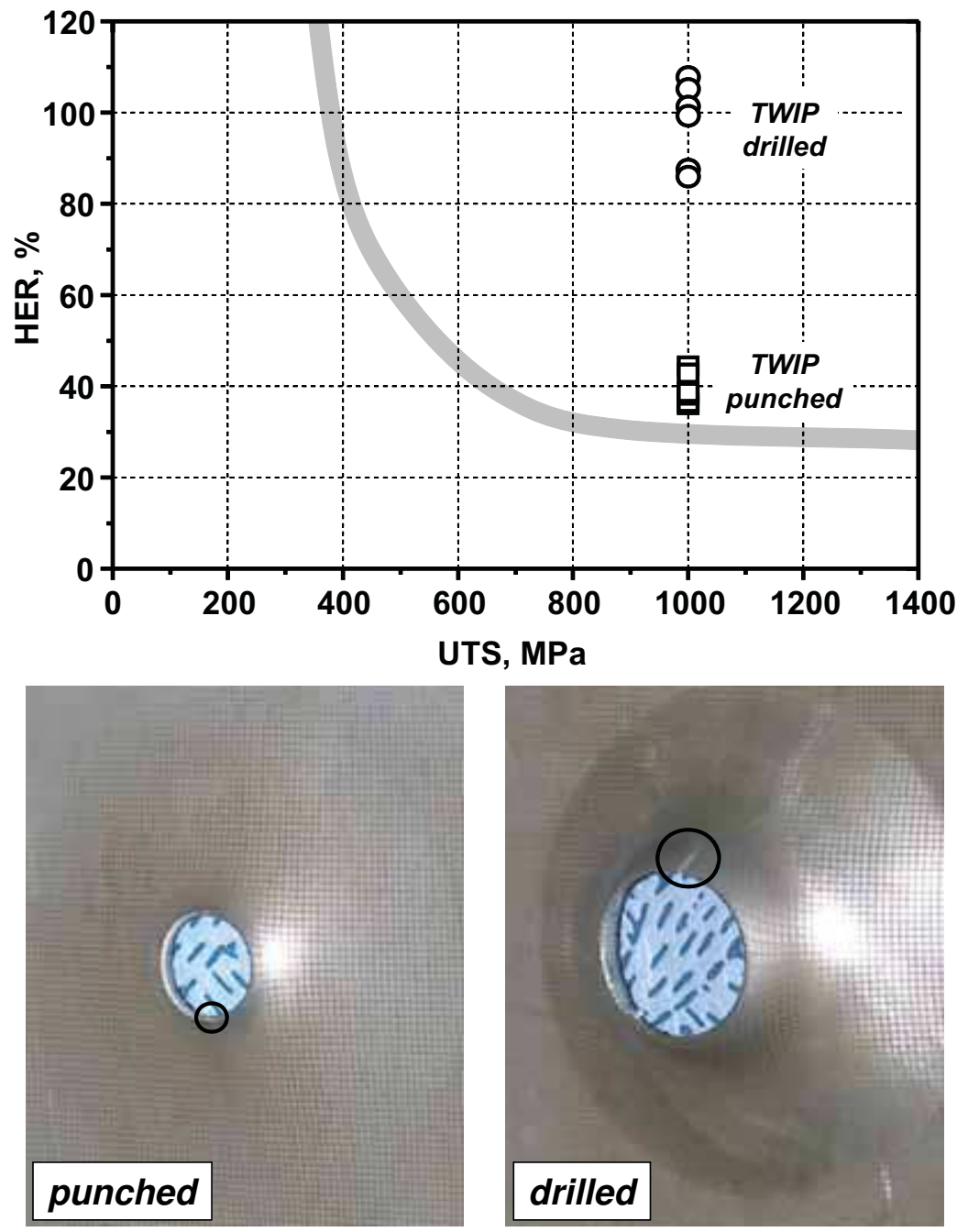

Fig. 17. HER for TWIP steel compared to the HER-UTS relation observed for a large number of automotive materials indicated by the gray band (top). Illustration of the difference in TWIP steel hole expansion performance for a low quality punched hole (below, left) and a high quality drilled hole (below, right). 


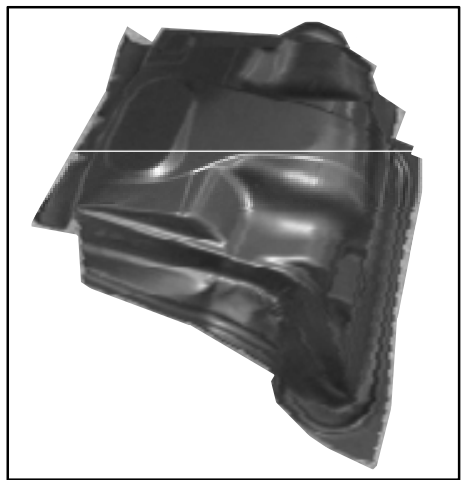

Fig. 18. Example illustrating the use of TWIP steel for the press forming of an automotive shock absorber housing.

\section{High strain rate properties}

Figure 19 compares the dynamic energy absorption of different types of automotive steels when tested at a strain rate of $10^{3} \mathrm{~s}^{-1}$. High strain rate properties of TWIP steels have been reported by Frommeyer et al. (2003) for a Fe-25\%Mn-3\%Si-3\% Al-0.03\%C TWIP steel where the formation of $\alpha^{\prime}$ and $\varepsilon$ is fully suppressed, even after straining. This TWIP steel has a moderate strain hardening (Yield strength: 280MPa; Tensile Strength: 650MPa) and dislocation glide has been reported as the main deformation mechanism. At lower temperatures the amount of twinning increases. Extensive twin formation occurs during high strain rate deformation, and no brittle fracture is observed even at a temperature as low as $-200^{\circ} \mathrm{C}$.

Ueji et al. (2007) studied the high strain rate deformation of $\mathrm{Fe}-31 \% \mathrm{Mn}-3 \% \mathrm{Si}-3 \% \mathrm{Al}$ TWIP steel for a grain size in the range of $1.1 \mu \mathrm{m}-35.5 \mu \mathrm{m}$. In contrast to the observation made for ferritic steels there is still a large elongation at small grain sizes. They explain their observations by the limited dynamic recovery in TWIP steels due to a low SFE. The elongation is only slightly smaller at higher strain rates $10^{-3}$ to $10^{+3} \mathrm{~s}^{-1}$.

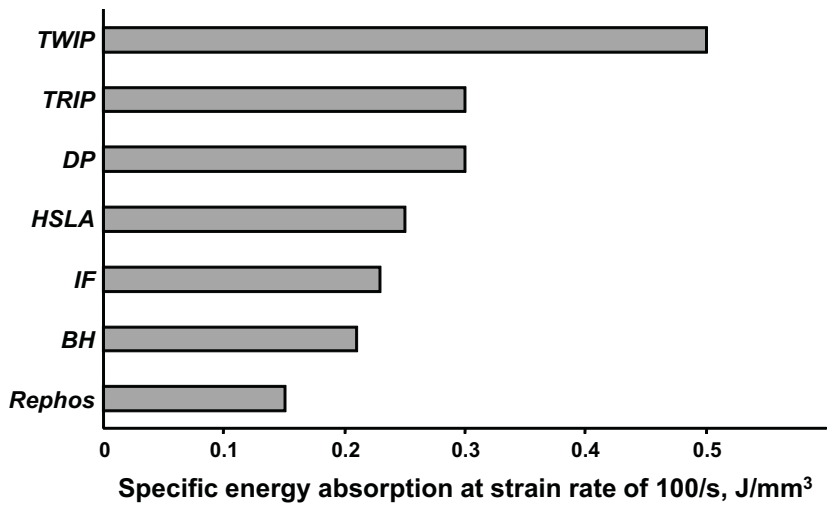

Fig. 19. Comparison of the energy absorption, in $\mathrm{J} / \mathrm{mm}^{3}$, for common types of automotive steels during high strain deformation (Strain rate: $10^{3} \mathrm{~s}^{-1}$ ). 
Sahu et al. (2010) have studied the mechanical behavior of two Fe-24\%Mn-0.5\%Si-(0.11$0.14) \% \mathrm{C}$ TWIP steels with $0.91 \%$ and $3.5 \% \mathrm{Al}$ additions in the strain rate range of $10^{-4}-4000 \mathrm{~s}^{-}$

1. The transformation of austenite to martensite is reported to take place up to a strain rate of $10^{3} \mathrm{~s}^{-1}$. The TWIP steel alloyed with 3.5\% Al had a higher stability, and the transformation of this TWIP steel was limited to the strain rate range of $10^{-3} \mathrm{~s}^{-1}$ to $720 \mathrm{~s}^{-1}$. Irrespective of the $\mathrm{Al}$ content, the transformation of the austenite phase is suppressed during high strain rate deformations due to the adiabatic heating of the sample. Based on the observation of serrated grain boundaries, they also argue that dynamic recrystallization may be taking place during the high strain rate tests.

\section{Strain localization}

Room temperature dynamic strain aging (DSA) occurs in the most commonly studied carbonalloyed TWIP steels Fe-22\%Mn- $0.6 \% \mathrm{C}$ and Fe- $18 \% \mathrm{Mn}-0.6 \% \mathrm{C}$. DSA-related type A serrations are shown in figure 20. It is very likely due to the presence of C-Mn complexes, which re-orient in the presence of dislocations via a single hop diffusion mechanism. This mechanism is similar to a model recently developed by Curtin et al. (2006). This re-orientation does not require long range diffusion, only a single diffusional hop of the interstitial carbon in the C-Mn complex to achieve a suitable orientation with respect to the strain field of the partial dislocation. The fast dislocation core diffusion has been proposed as an alternatively, to explain this widely observed room temperature DSA (Chen et al., 2007).
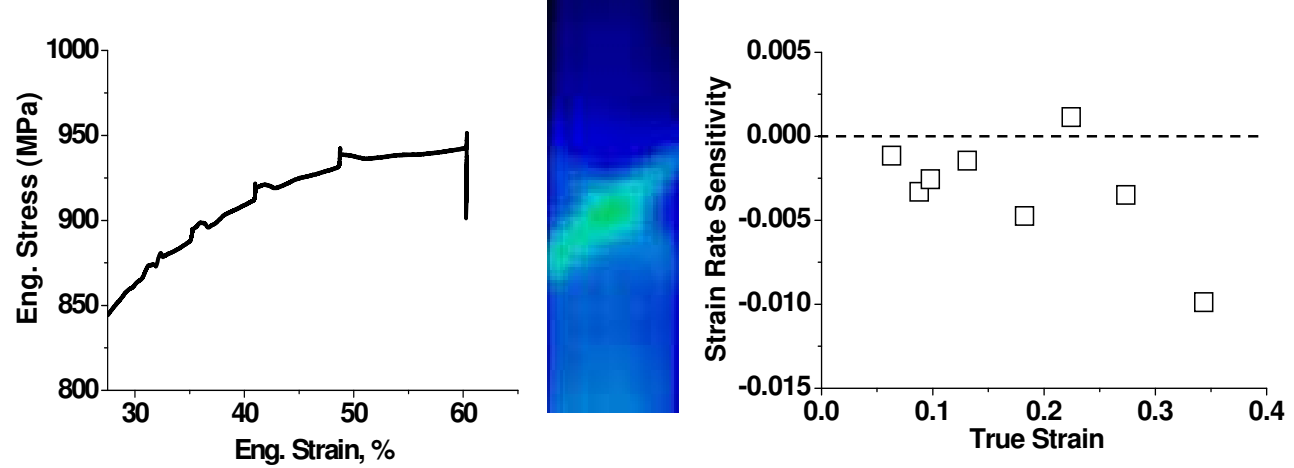

Fig. 20. Direct evidence for DSA in TWIP steel: type A serrations due to the passage of individual PLC bands (left), IR thermography of an isolated PLC band (middle), strain rate sensitivity measurement showing negative values (right).

Detailed DSA studies have been carried out by Chen et al. (2007), Kim et al. (2009) and Zavattieri et al. (2009) for Fe-17-18Mn-0.6\%C-1-1.5\% Al have analyzed the PLC band properties. They report that the band velocity decreases with strain and that the band strain rate is 15-100 times the applied value. Localization may in principle result in press forming difficulties, but the occurrence of PLC bands in uni-axial tensile testing has not been reported to lead to the poor press forming performance for Fe-22Mn-0.6C TWIP steel (Allain, 2008). This is very likely related to the fact that the occurrence of DSA-related surface defects are stress state and strain rate dependent. Based on data for the critical strain of Bracke (2006) the schematic in figure 21 is proposed. 


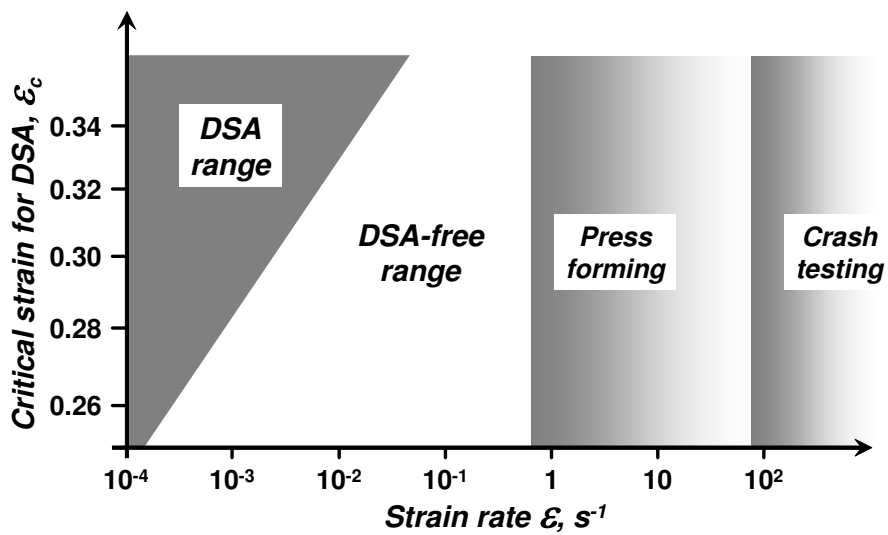

Fig. 21. Schematic showing the approximate strain rate and critical strain region for DSA.

The other aspects of DSA should however not be overlooked, as DSA is related to a negative strain rate sensitivity and hence a very limited post-uniform elongation, as illustrated in figure 22 .

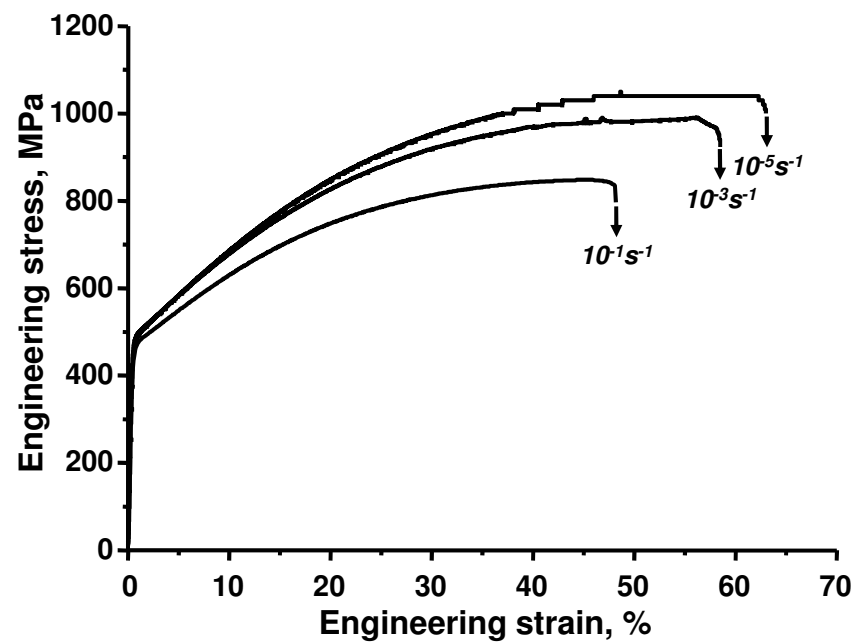

Fig. 22. Stress-strain curves for Fe- $18 \% \mathrm{Mn}-0.6 \% \mathrm{C}-1.5 \% \mathrm{Al}$ TWIP steel clearly showing the negative strain rate sensitivity of this material: the flow stress decreases with increasing strain rate. Note the suppression of the serrations when the material is tested at higher strain rates.

In carbon-alloyed f.c.c. alloys the room temperature DSA cannot be explained by long range diffusion of carbon. Instead it results from the presence of point defect complexes which can re-orient themselves in the stress field of dislocations or in the stacking faults. Possible defect complexes in high Mn TWIP steels are the following: carbon-vacancy complex, carbon-carbon complex, and carbon-Mn complex. The two first complexes are unlikely due to the very low vacancy concentration and the strong repulsive carbon-carbon interaction. 
The carbon-Mn complexes are very likely due to the strong attractive interaction between interstitial carbon and the substitutional Mn. The most likely carbon-Mn complex in Fe-MnC TWIP steel has one carbon atom and one Mn atom (figure 23).

Serrated stress-strain curves can be avoided by increasing the $\mathrm{Al}$ content as illustrated in figure 24. As $\mathrm{Al}$ additions are known to increase the stacking fault energy, this data seems to suggest that the main interaction giving rise to the flow localization is the interaction between the C-Mn point defect complexes and the stacking faults. A similar
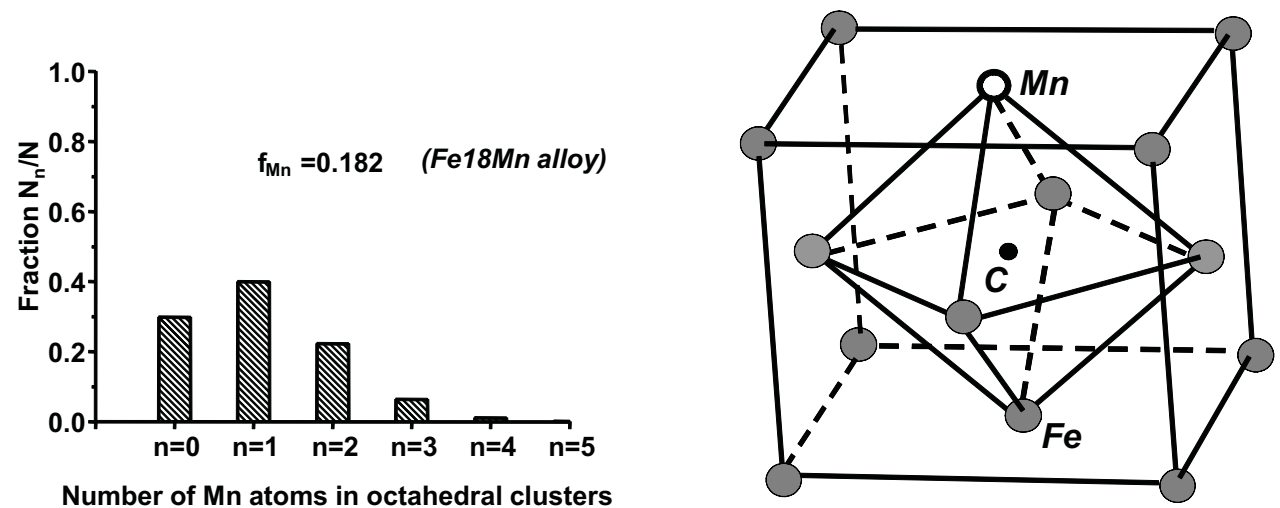

Number of Mn atoms in octahedral clusters

Fig. 23. Distribution of the various types of C-Mn complexes in a Fe- $18 \% \mathrm{Mn}-0.6 \% \mathrm{C}$ TWIP steel (left). The most likely complex is a octahedral cluster containing one carbon atom and one Mn atom (right).

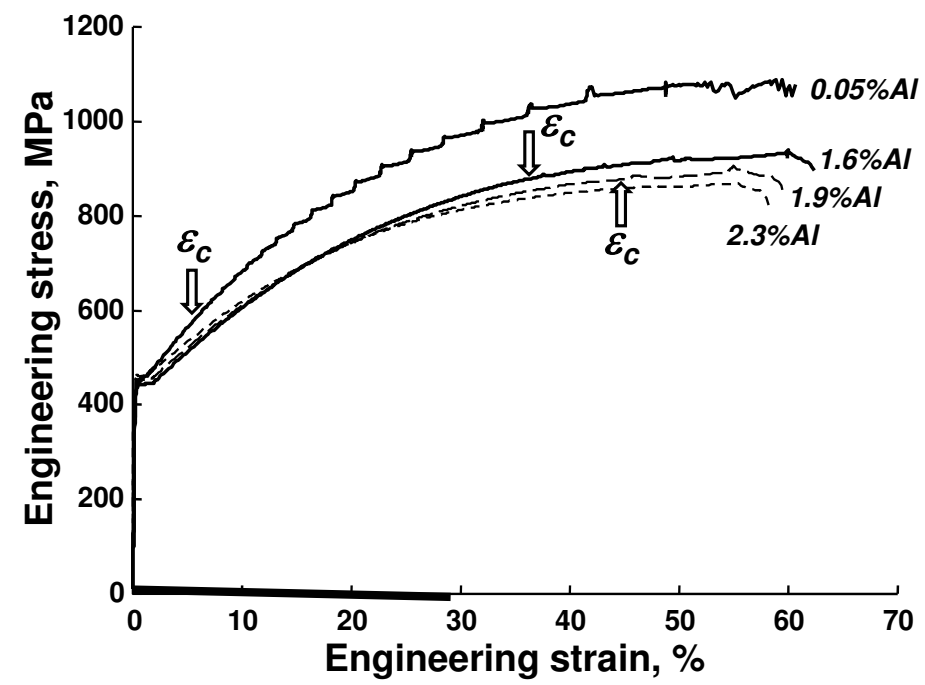

Fig. 24. Stress-strain curves Fe-18\%Mn-0.6\% C TWIP steel with increasing Al alloying additions. The additions delay the onset of the serrations, and at $2.3 \% \mathrm{Al}$ no serrations are observed. 


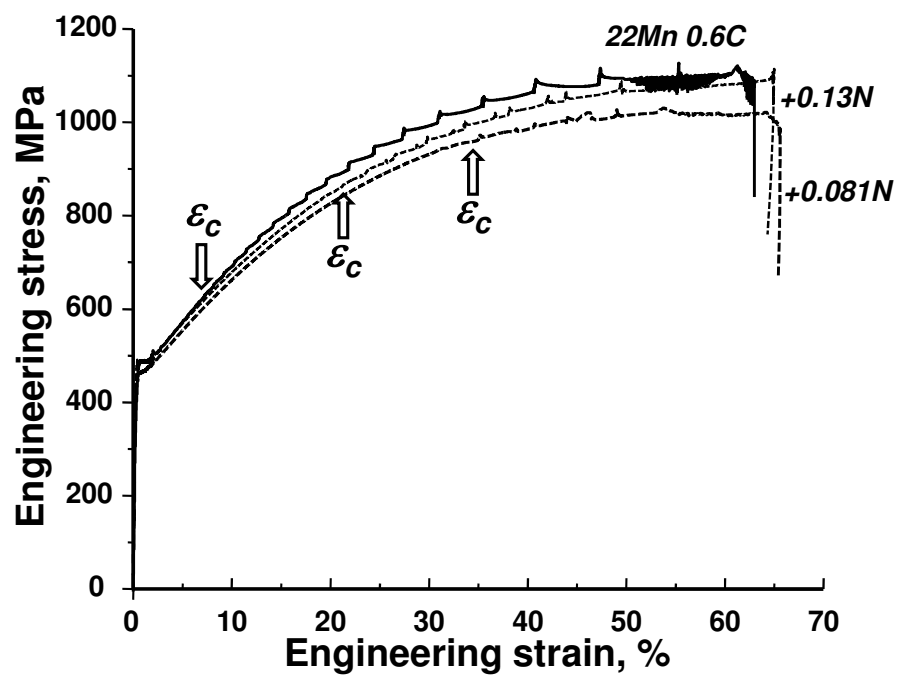

Fig. 25. Influence of $\mathrm{N}$ alloying additions on the stress-strain curve of $\mathrm{Fe}-22 \% \mathrm{Mn}-0.6 \% \mathrm{C}$ TWIP steel.

effect is expected from nitrogen additions. At nitrogen contents lower than 0.3 mass- $\%$, the SFE increases. The effect of nitrogen additions on the suppression of the serrations is illustrated in figure 25 .

\section{Delayed fracture}

The need to study delayed fracture remains important. The phenomenon is very likely related to hydrogen induced cracking and it will require further fundamental analysis as delayed fracture has been identified as the major problem for Fe-22\%Mn-0.6\% C TWIP steel. The effect appears readily in deep drawn cup as deep edge cracks a certain time after the cup has been drawn. The edge of a fully drawn cup is subjected to residual tensile hoop stresses. The exact mechanism for delayed fracture has not yet been identified, but Kim et al. (2008) have suggested that it is related to martensitic transformation in the presence of residual stresses and possibly hydrogen. They investigated the influence of the $\gamma \rightarrow \alpha^{\prime}$ and $\gamma \rightarrow \varepsilon$ martensitic transformations formed during the tensile testing in Fe- $18 \% \mathrm{Mn}-0.6 \% \mathrm{C}$ and Fe-18\%Mn-0.6\%C-1.5\% Al TWIP steel. The Al-alloyed TWIP steel remained free of martensite. Both TWIP steel contained martensite after cup drawing however, but the amount of martensite was slightly less for the Al alloyed TWIP steel. The suppression of delayed fracture by Al-additions is illustrated in figure 26. This may be due to the fact that, as martensitic transformations require the ease of formation of planar faults, an increase of the SFE resulting from Al-additions will limit the nucleation of a martensite phase which may be embrittled by the presence of small amount of solute hydrogen.

Jung et al. (2008) compared the hydrogen embrittlement of TRIP and TWIP steel after cathodic hydrogen charging. They report that Fe- $15 \% \mathrm{Mn}-0.45 \% \mathrm{C}-1 \% \mathrm{Al}$ and $\mathrm{Fe}-18 \% \mathrm{Mn}-$ $0.6 \%$ C TWIP steels, with and without Al-additions, contained less hydrogen and were much more resistant to embrittlement than TRIP steel after U-bend and cup drawing tests. 


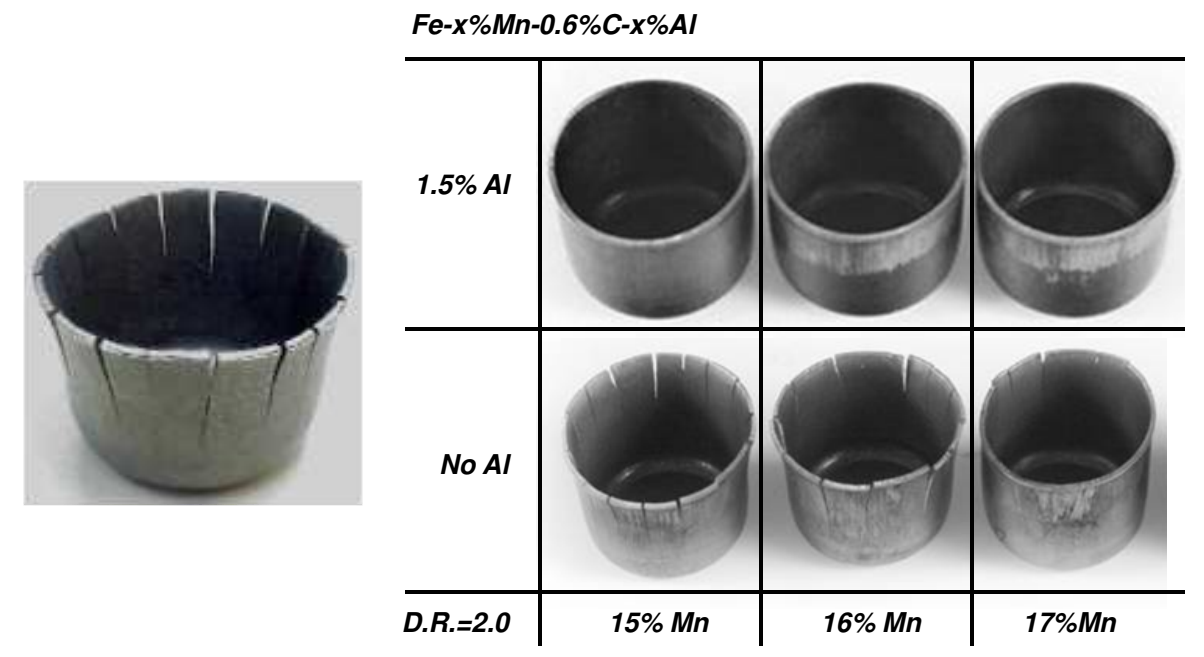

Fig. 26. Example of delayed fracture deep drawn Fe-22\%Mn-0.6\% C TWIP steel (Left). Suppression of delayed fracture in deep drawn Fe-(15-17)\%Mn-0.6\% C TWIP steel by alloying additions of $1.5 \% \mathrm{Al}$ (Right).

\section{Fatigue properties}

The performance of a $1160 \mathrm{MPa}$ tensile strength Fe-22\%Mn-0.52\% C TWIP steel during cyclic loading has been reported to be influenced by the pre-straining (Niendorf et al., 2009). A significant longer fatigue life was achieved when the TWIP steel is pre-deformed. This is explained by the formation of new twins during the pre-deformation and their evolution hindering the dislocation motion. This leads to a stable deformation response in cyclic loading and a longer fatigue life. When tested in the as-received state, the dislocation density decreases and the existing twins widen, leading to a cyclic softening due to a lack of dislocation-twin interaction, and a lack of nucleation of new twins. Hamada et al. (2009) have studied the high cycle fatigue behavior of Fe-22.3\%Mn-0.6C (SFE: $26 \mathrm{~mJ} / \mathrm{m}^{2}$ ), Fe$17.8 \% \mathrm{Mn}-0.6 \% \mathrm{C}$ with a 200ppm Nb addition (SFE: $23 \mathrm{~mJ} / \mathrm{m}^{2}$ ) and Fe-16.4\%Mn-0.29\%C$1.54 \% \mathrm{Al}$ (SFE: $19 \mathrm{~mJ} / \mathrm{m}^{2}$ ) TWIP steels were studied in flexural bending fatigue using a zero mean stress. They report that the three steels had the same $2 \times 10^{6}$ cycles fatigue stress limit of $400 \mathrm{MPa}$, i.e. well above the yield stress of the steels. The ratio of fatigue limit to tensile strength was in the range of $0.42-0.48$, i.e. common to austenitic steels. No twins or $\varepsilon$ martensite were formed during the fatigue test, but fatigue cracks nucleated at intersections of slip band and grain boundaries and annealing twin boundaries.

\section{Ultra-fine grained TWIP steel}

Ultra-fine grained (UFG) ferritic steels are characterized by a combination of ultra-high strength and limited elongation. This does not seem to be the case for UFG austenitic TWIP steel. Ueji et al. (2007) have reported that UFG Fe-31\%Mn-3\%Al-3\%Si TWIP steel retained a considerable ductility in contrast to UFG Al or IF steel. Bouaziz et al. (2009) have studied the properties of nano-structured Fe-22\%Mn- $0.6 \% \mathrm{C}$ TWIP steel obtained by a combination of 
cold deformation and recovery-annealing. The process decreases the dislocation density and retains the very dense nano-scale twin microstructure, leading to very high yield stresses and adequate elongations.

\section{TWIP steel industrialization}

The considerable interest in high Mn TWIP steels is due to their superior mechanical properties. Compared to standard low carbon steels, high Mn TWIP steels have high carbon and $\mathrm{Mn}$ contents. When $\mathrm{Al}$ is added the content also tends to be high. It is clear that the cost issue will be important in addition to remaining technical problems. Ferro-Manganese is reportedly rich in $\mathrm{P}$ which will require more attention during steelmaking. Whereas TWIP steels have demonstrated their formability for complex automotive parts despite their high strength, their behavior in stretch forming, in particular during hole expansion, is not as good as one may have expected, when compared e.g. to that of IF steel. This is mainly due to the absence of post-uniform strain, which is a direct consequence of the low strain rate sensitivity. The application of $\mathrm{Zn}$ and $\mathrm{Zn}$ alloy coatings by hot dip galvanizing requires special care as there are clear indications that a $\mathrm{MnO}$ surface layer is formed during continuous annealing and processing in a hot dip galvanizing line. This $\mathrm{MnO}$ surface layer will very likely influence coating adhesion, and electrolytic Zn deposition will very likely be the preferred route for coating TWIP steels. Both HDG and electrolytic coating of TWIP steel have been attempted and examples of defect-free $\mathrm{Zn}$ coatings are shown in figure 27.
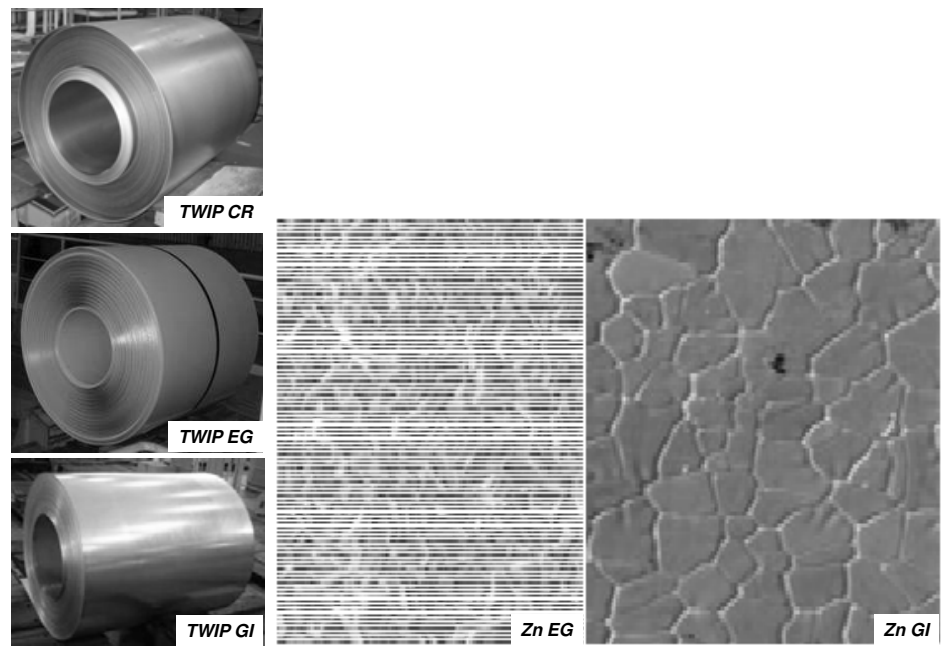

Fig. 27. Examples of cold rolled TWIP steel coils. Electrodeposited and hot dip pure Zn coating quality on TWIP steel showing the absence of bare spots.

\section{Conclusion}

The present review of the properties of high Mn TWinning-Induced Plasticity (TWIP) steels clearly shows that the Fe-(15-30)\%Mn alloy system with additions of C, Al and/or Si to fully 
stabilize the f.c.c. phase and control the SFE within the narrow range of $15-30 \mathrm{~mJ} / \mathrm{m}^{2}$, results in steels with very wide range of mechanical properties, making this relatively new class of steels of interest for many automotive applications. The physical metallurgy of TWIP steels is still relatively limited and the following aspects need to receive an in depth analysis: the twinning mechanism, texture evolution, and delayed fracture. The determination of the twinned volume fraction remains a challenge and is needed to evaluate the different models proposed to explain the mechanical behavior of TWIP steels. The distribution of the twinning as it related to the formation of texture components must also be given a clear analysis. The mechanism of delayed fracture is still not known. In particular the complex interaction of factors related to transformation, residual stresses, and the influence of hydrogen has made the issue particularly difficult to address. Having said this it is clear that Al-added TWIP steels may be considered immune to the problem.

\section{References}

Grässel O., Frommeyer G., Derder C., Hofman H. (1997), J. Phys. IV France, vol.60, 383

Grässel O., Kruger L., Frommeyer G., Meyer L. (2000), International Journal of Plasticity, 16, , 1391

Frommeyer G., Brux U., Neumann P. (2003), ISIJ International, vol. 43, No. 3, 438-446

Prakash A., Hochrainer T., Reisacher E., Riedel H. (2008), Steel Research International, 79, No.8, 645

Schuman H. (1971), Neue Hutte 17, 605-609

Remy L., Pineau A. (1977), Mat. Sci. Eng., 28, 99

Kim T.W., (1993), Mat. Sci. Eng. A, 160, 13

Kim Y.G., Kim T. W., Hong S. B. (1993), Proceedings of the ISATA, Aachen, Germany, 1993, 269

Allain S. (2004), Ph.D. INPL, Nancy, France

Kim S.K., Choi J., Kang S. C., Shon I. R., Chin K. G. (2006), POSCO Technical Report, vol. 10, No.1, 106-114

Witusiewicz V.T., Sommer F., Mittemeijer E.J. (2004), J. Phase Equilib. Diff., 25(4), 346-354

Jung J.K., Lee O. Y., Park Y.K., Kim D.E., Jin K. G., Kim S.K., Song K.H. (2008), J. Korean Inst. Met. \& Mater., vol. 46, No.10, 627-633

Miodownik A.P. (1998), Z. Metallkunde 89, 840-846

Adler P.H., Olson G.B., Owen W.S. (1986), Metallurgical Transactions A, vol. 17, 1725

Alain S., Chateau J.-P., Bouaziz O., Migot S., Guelton N. (2004), Materials Science and Engineering A 387-389, 158-162

Yakubtsov I.A., Airapour A., Perovic D.D. (1999), Acta Materialia, Vol. 47, No. 4, 1271-1279

A.Dumay, J.-P. Chateau, S. Allain, S. Migot, O. Bouaziz (2008), Materials Science and Engineering A, 483-484, 2008, 184-187

Jin Jae-Eun, Lee Young-Kook (2009), Materials Science and Engineering A, 527, 157-161

Kim Jinkyung, De Cooman B.C., Unpublished results

Huang B.X., Wang X.D., Wang L., Rong Y.H. (2008), Metallurgical and Materials Transactions A, vol. 39A, 717

Tian X., Li H., Zhang Y. (2008), J. Mater. Sci., 43, 6214-6222 
Wang X.D., Huang B.X., Rong Y.H. (2008), Philosophical Magazine Letters, vol. 88, no.11, $845-851$

Idrissi H., Ryelandt L., Veron M., Schryvers D., Jacques P.J. (2009), Scripta Materialia, 60, 941-944

Meyers M.A., Vohringer O., Lubarda V.A. (2001), Acta Mater. 49, 4025

Venables J.A. (1961), Phil. Mag., 6, 379-396

Venables J.A. (1964), J. Phys. Chem. Solids, vol. 25, 693-700

Venables J.A. (1974), Phil. Mag, 30:5, 1165-1169

Bracke L., Kestens L., Penning J. (2009), Acta Materialia, 57, 1512-1524

Muira S., Takamura J.I., Narita N. (1968), Trans. J. Inst. Met. Suppl., 9, S555

Byun T.S. (2003), Acta Materialia, Volume 51, Issue 11, Pages 3063-3071

Sevillano J.G. (2009), Scripta Materalia, 60, 336-339

Bouaziz O., Geulton N., Scott C. (2008), Scripta Materalia, 58, 484-487

Bouaziz O., Geulton N. (2001), Materials Science and Engineering, A319-321, 246-249

Allain S., Chateau J.-P., Bouaziz O. (2004), Materials Science and Engineering A 387-389, 143147

Kocks U.F., Mecking H. (1981), Acta Metallurgica, 32, 1865

Allain S., Chateau J.-P., Dahmoun D., Bouaziz O. (2004), Materials Science and Engineering A 387-389, 272-276

Shiekhelsouk M.N., Favier V., Inal K., Cherkaoui M. (2009), International Journal of Plasticity 25, 105-133

Kim Jinkyung, Graduate Institute of Ferrous Technology, POSTECH, Unpublished results

Estrin Y., Kubin L.P. (1986), Acta Metallurgica, Vol. 34, No. 12, pp. 2455-2464

Dini G., Ueji R., Najafizadeh A., Monir-Vaghefi S.M. (2010), Materials Science and Engineering A 527, 2759-2763

Rintao Ueji, Kenji Harada, Noriyuki Tsuchida, Kazutoshi Kunishige (2007), Materials Science Forum, vol. 561-565, 107-110

Sahu P., Curtze S., Das A., Mahato B., Kuokkala V.-T., Gosh Chowdhury S. (2010), Scripta Materialia, 62, 5-8

Curtin W.A., Olmsted D. L., Hector, Jr L. G. (2006), Nature Materials, Vol. 5, 875

Allain S., Cygy P., Scott C., Chateau J.-P, Rusinek A., Deschamps A. (2008), Int. J. Mat. Res., $99,7,734$

Chen L., Kim H.-S., Kim S.-K., De Cooman B.C. (2007), ISIJ International, vol. 47 (12), 180412

Kim J.-K., Chen L., Kim H.-S., Kim S.-K., Estrin Y., De Cooman B.C. (2009), Metallurgical and Materials Transactions A, vol. 40, no. 13, 3147-3158

Zavattieri P.D., Savic V., Hector Jr L.G., Fekete J.R., Tong W., Xuan Y. (2009), International Journal of Plasticity, 25, 2298

Bracke L. (2006), Ph.D. Thesis, Ghent University, Ghent, Belgium

Kim Y., Kang N., Park Y., Kim G., Kim S., Cho K. (2008), J. Korean Inst. Met. \& Mater., Vol. 46, No. 12, 780-787

Jung J.K., Lee O.Y., Park Y. K., Kim D.E., Jin K.G. (2008), Korean J. Mater. Res., vol. 18, no. 7, 394-399 
Niendorf T., Lotze C., Canadinc D., Frehn A., Maier H.J. (2009), Materials Science and Engineering A, 499, 518-524

Hamada A.S., Karjalainen L. P., Puustinen J. (2009), Materials Science an ngineering A, 517, 68-77

Ueji R., Tsuchida N., Fujii H., Kondo A., Kunishige K. (2007), J. Japan Inst. Metals, vol. 71, No. 9, 815-821

Bouaziz O., Scott C.P., Petitgrand G. (2009), Scripta Materialia, 69, 714-716 


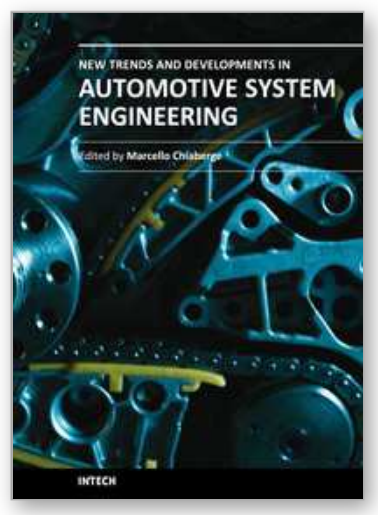

\author{
New Trends and Developments in Automotive System Engineering \\ Edited by Prof. Marcello Chiaberge
}

ISBN 978-953-307-517-4

Hard cover, 664 pages

Publisher InTech

Published online 08, January, 2011

Published in print edition January, 2011

In the last few years the automobile design process is required to become more responsible and responsibly related to environmental needs. Basing the automotive design not only on the appearance, the visual appearance of the vehicle needs to be thought together and deeply integrated with the â€œpowerâ€ developed by the engine. The purpose of this book is to try to present the new technologies development scenario, and not to give any indication about the direction that should be given to the research in this complex and multi-disciplinary challenging field.

\title{
How to reference
}

In order to correctly reference this scholarly work, feel free to copy and paste the following:

B. C. De Cooman, Kwang-geun Chin and Jinkyung Kim (2011). High Mn TWIP Steels for Automotive Applications, New Trends and Developments in Automotive System Engineering, Prof. Marcello Chiaberge (Ed.), ISBN: 978-953-307-517-4, InTech, Available from: http://www.intechopen.com/books/new-trends-anddevelopments-in-automotive-system-engineering/high-mn-twip-steels-for-automotive-applications

\section{INTECH}

open science | open minds

\section{InTech Europe}

University Campus STeP Ri

Slavka Krautzeka 83/A

51000 Rijeka, Croatia

Phone: +385 (51) 770447

Fax: +385 (51) 686166

www.intechopen.com

\section{InTech China}

Unit 405, Office Block, Hotel Equatorial Shanghai

No.65, Yan An Road (West), Shanghai, 200040, China

中国上海市延安西路65号上海国际贵都大饭店办公楼 405 单元

Phone: +86-21-62489820

Fax: +86-21-62489821 
(C) 2011 The Author(s). Licensee IntechOpen. This chapter is distributed under the terms of the Creative Commons Attribution-NonCommercialShareAlike-3.0 License, which permits use, distribution and reproduction for non-commercial purposes, provided the original is properly cited and derivative works building on this content are distributed under the same license. 